\title{
Clinical practice guidelines for the management of hypothyroidism
}

\section{Diretrizes clínicas práticas para o manejo do hipotiroidismo}

Gabriela Brenta', Mario Vaisman'2, José Augusto Sgarbi³, Liliana

Maria Bergoglio ${ }^{4}$, Nathalia Carvalho de Andrada ${ }^{5}$, Pedro Pineda

Bravo $^{6}$, Ana Maria Orlandi', Hans Graf $^{8}$, on behalf of the Task Force

on Hypothyroidism of the Latin American Thyroid Society (LATS)
Thyroid Dysfunction Task Force. Latin American Thyroid Society ${ }^{1}$ Dr. Cesar Milstein Hospital, Buenos Aires, Argentina 2 Universidade Federal do Rio de Janeiro (UFRJ), Rio de Janeiro, RJ, Brazil

${ }^{3}$ Faculdade de Medicina de Marília (Famena), São Paulo, SP, Brazil ${ }^{4}$ National University of Córdoba Clinical Hospital, Córdoba, Argentina ${ }^{5}$ Guidelines Project, Brazilian Medical Association, Brazil ${ }^{6}$ University of Chile Clinical Hospital, Santiago del Chile, Chile ${ }^{7}$ Dr. Teodoro Alvarez Hospital, Buenos Aires, Argentina ${ }^{8}$ Universidade Federal do Paraná (UFPR), Curitiba, PR, Brazil

\section{RESUMO}

Introdução: O hipotiroidismo é amplamente reconhecido por seus efeitos sobre os diferentes sistemas orgânicos, levando ao hipometabolismo. No entanto, o hipotiroidismo subclínico, sua apresentação mais prevalente, tem sido recentemente relacionado ao risco cardiovascular e também com complicações materno-fetais em gestantes. Objetivos: Nestas diretrizes clínicas, vários aspectos do hipotiroidismo foram discutidos com objetivos claros de ajudar os médicos a tratar pacientes com hipotiroidismo e de compartilhar algumas das nossas experiências clínicas na América Latina. Materiais e métodos: A Sociedade Latino-Americana deTireoide formou uma Força-Tarefa para desenvolver diretrizes baseadas em evidências clínicas sobre o hipotiroidismo. Foi realizada uma revisão sistemática da literatura existente, com foco em bancos de dados primários do MedLine/PubMed e Lilacs/SciELO. Foram feitas análises para avaliar a qualidade metodológica no sentido de selecionar os melhores estudos. A força de recomendação em uma escala de A-D foi baseada no Centro de Oxford para a Medicina Baseada em Evidência - Níveis de Evidência 2009 -, permitindo uma opinião imparcial, desprovida de pontos de vista \begin{abstract}
referred to are from all over the world, the point of view of thyroidologists from Latin America
\end{abstract}
Keywords

Hypothyroidism; subclinical hypothyroidism; clinical practice guidelines; evidence based medicine
Correspondence to:

Gabriela Brenta

Virrey Del Pino, $3370,3^{\circ} \mathrm{A}$ CABA 1426, Argentina gbrenta@gmail.com

Received on Apr/28/2013 Accepted on Apr/29/2013 
subjetivos. As áreas de interesse compreenderam estudos de diagnóstico, triagem, tratamento e uma seção especial de hipotiroidismo na gravidez. Resultados: Foram feitos vários questionamentos relacionados ao diagnóstico, triagem e tratamento do hipotiroidismo na população adulta e, especificamente, em mulheres grávidas. Foram elaboradas vinte e seis recomendações baseadas nas respostas a essas perguntas. Apesar da falta de evidências em algumas áreas como o tratamento do hipotiroidismo, de 279 referências, $73 \%$ eram de Grau A e B, 8\% de Grau C e 19\% de Grau D. Conclusões: Essas diretrizes baseadas em evidências clínicas sobre o hipotiroidismo poderão [fornecer um critério consensual de como tratar o hipotiroidismo na América Latina. Apesar de a maior parte dos estudos referidos ser da experiência internacional em hipotiroidismo, o ponto de vista dos tiroidologistas da América Latina foi contemplado. Arq Bras Endocrinol Metab. 2013;57(4):265-99

\section{Descritores}

Hipotiroidismo; hipotiroidismo subclínico; diretrizes clínicas práticas; medicina baseada em evidências

\section{INTRODUCTION}

$\mathrm{H}$ ypothyroidism is one of the most frequent endocrine diseases. It is usually detected by clinicians and often now looked for by other specialists such as gynecologists and cardiologists, who are more aware of its unwanted effects. Therefore, the purpose of these clinical practice guidelines has been to develop a systematic statement designed to assist health care professionals and patients in making decisions about appropriate health care for the management of hypothyroidism. We also sought to illustrate traditional concepts regarding overt hypothyroidism and to provide an updated view of the controversies and assertions in the field of subclinical hypothyroidism.

The guidelines are divided into four areas, addressing diagnosis, screening, treatment and a special section for hypothyroidism in pregnancy. In these guidelines, the topic of hypothyroidism in paediatrics was not included.

The main questions posed were: How to make the diagnosis of hypothyroidism? Who should be screened for hypothyroidism? How should case finding be done? When should thyroid ultrasonography be performed? Which patients with subclinical hypothyroidism should be considered for treatment with thyroid hormones? How should patients with hypothyroidism be treated and monitored? When and how to screen hypothyroidism in pregnant women? How are hypothyroidism and subclinical hypothyroidism defined in pregnant women? What is the role of thyroid autoimmunity in fertility and pregnancy? When and how to treat hypothyroidism in pregnant women? Each question was answered according to the available literature and was concluded with a series of recommendations.

\section{Consensus process}

The guidelines were developed by members of the Latin American Thyroid Society (LATS) who took part in the Task Force on Hypothyroidism. The representatives acting on behalf of LATS were: Hans Graf, José Sgarbi and Mario Vaisman from Brasil; Liliana Bergoglio, Gabriela Brenta and Ana Orlandi from Argentina; and Pedro Pineda Bravo from Chile. In order to prepare the manuscript, three face-to-face meetings were held. A robust exchange of e-mails was required to agree on all concepts that were included and to make modifications according to suggestions. The clinical guidelines task force started its activities in late $201 \mathrm{l}$. The grading of evidence was performed with the help of Nathalia Carvalho de Andrada, from the Guidelines Project of the Brazilian Medical Association. After several revisions, the initial draft was reviewed and approved by the LATS President.

\section{Evidence}

These Evidence-Based Clinical Guidelines integrate theoretical knowledge with medical practice when using the methodology of Evidence-Based Medicine (EBM). This method provides clear, transparent, reliable information and best likelihood of reproducibility of results. After having defined several clinical situations of interest about hypothyroidism in the introduction to the Guidelines, there was a systematic review of the available literature, especially in the primary databases of MedLine/PubMed and Lilacs/ SciELO. Using filters to assess methodological quality, the best studies were compiled. As a general rule, a clinical trial with good methodological quality defines the real benefits and potential risks of diagnostic and 
therapeutic interventions. The results of the literature search provided studies that were graded by level of evidence. The strength of recommendation was based on the Oxford Centre for Evidence-based Medicine, Levels of Evidence 2009, allowing an unbiased opinion devoid of subjective viewpoints. As some medical conditions did not lend themselves ideally to giving formal recommendations based on studies with high or conclusive levels of evidence (recommendation grades $\mathrm{A}$ and $\mathrm{B}$ ), being relevant clinical situations, their recommendations were retained, even when they were supported only or primarily by expert opinion (recommendation grade $\mathrm{D}$ ).

There is a relationship between the methodological quality of the study design (strength of evidence - levels 1 to 5 ) and the same degree of recommendation (grades A to D). After critical evaluation of the literature, recommendations that always took into account the best available evidence to date for each issue were made, underscoring both certainties and uncertainties.

The areas of interest in which the evidence was distributed included: Diagnosis, Differential diagnosis/ Symptom prevalence study, Therapy/Prevention, Etiology/Harm, and Prognosis. Based on the strength of evidence, four grades of recommendations from $\mathbf{A}$ to $\mathbf{D}$ were assigned. The original Oxford Centre for Evidence-based Medicine Levels of Evidence can be found at http://www.cebm.net/index.aspx?o=1025.

With the purpose of interpreting the Oxford EBM classification of evidence in simplified manner, a summary of studies for diagnosis and approved by the LATS President:

\section{For diagnosis}

- Grade A: includes prospective cohort studies performed at a single center location, validated with a gold standard parameter (or a systematic review of this kind of study).

- Grade B: includes exploratory cohort studies (these studies collect information and trawl the data, e.g. using a regression analysis, to find which factors are "significant") that only seek information in a part of the population; or follow-up of untreated control patients in a randomized control trial (RCT); or studies with poor follow-up. Level B studies can be multi-centric, prospective or restrospective (or a systematic review of this kind of study). Also included are non-consecutive cohort studies, or with very li- mited population (or a systematic review of this kind of study).

- Grade C: includes case-control studies; or case-series (and poor quality prognostic cohort studies).

- Grade D: includes expert opinion without explicit critical appraisal, or based on physiology, bench research or "first principles".

\section{And for therapy}

- Grade A: includes individual randomized control trials (RCT) (with narrow Confidence Interval) (or a systematic review of this kind of study).

- Grade B: includes individual cohort studies (including low quality RCT; e.g., $<80 \%$ follow-up) (or a systematic review of this kind of study). It also includes individual case-control studies (or a systematic review of this kind of study).

- Grade C: includes case-series (and poor quality cohort and case-control studies).

- Grade D: includes expert opinion without explicit critical appraisal, or based on physiology, bench research or "first principles".

\section{Grades of recommendation}

\begin{tabular}{ll}
\hline A & Consistent level 1 studies \\
B & Consistent level 2 or 3 studies or extrapolations from level 1 studies \\
C & Level 4 studies or extrapolations from level 2 or 3 studies \\
D & $\begin{array}{l}\text { Level } 5 \text { evidence or troublingly inconsistent or inconclusive studies of } \\
\text { any level }\end{array}$ \\
\hline
\end{tabular}

"Extrapolations" are where data is used in a situation that has potentially clinically important differences than the original study situation.

In the diagnostic section of the Guidelines, some calculations of probability of disease were included. In order to make definitive diagnosis of hypothyroidism, it is necessary to know the prevalence of the disease and the sensitivity and specificity values of TSH and free T4 measurements, allowing for calculation of the positive likelihood ratio ( $\mathrm{LR}+=$ sensitivity/( 1 -specificity). Therefore, knowing the prevalence of hypothyroidism and subclinical hypothyroidism (likelihood of disease pre-exam) and having a patient with an impaired diagnostic test (with a known LR), the probability of di- 
sease in the patient studied (post-test probability) can be determined. The LR is used to assess how good a diagnostic test is and to help in selecting an appropriate diagnostic test(s) or sequence of tests. LR has advantages over sensitivity and specificity because it is less likely to change with the prevalence of the disorder.

In the treatment section of the Guidelines, some calculations of the magnitude of therapeutic clinical trials results found were also run. They were expressed by the absolute risk reduction (ARR) and the Number Needed to Treat value $(\mathrm{NNT}=\mathrm{l} / \mathrm{ARR})$, which defines the number of patients you need to treat to prevent an outcome or unwanted event (for example: death). In medicine, a number needed to treat $(\mathrm{NNT})$ value of 5 or less represents a clinically significant finding. Mathematically, a number needed to treat (NNT) of 5 is equal to a $20 \%$ improvement. A number needed to treat (NNT) of 2 is equal to a $50 \%$ improvement.

\section{BACKGROUND ON HYPOTHYROIDISM}

The function of the thyroid gland is regulated by thyroid-stimulating hormone (TSH), which is synthesized and secreted from the anterior pituitary gland. Thyroid hormones exert a negative feedback in patients with an intact hypothalamic-pituitary-thyroid axis, thereby controlling thyroid gland metabolism. A decrease in thyroid hormone production stimulates more TSH secretion.

Hypothyroidism is characterized by a deficient thyroid hormone production by the thyroid gland, which can be severe or moderate. Severe deficit of thyroid hormones defines overt hypothyroidism $(\mathrm{OH})$. The moderate form, called subclinical hypothyroidism $(\mathrm{SH})$, seldom has signs and symptoms and is defined biochemically by TSH concentration above the upper limit of the reference range, with thyroid hormone levels that remain within the reference ranges. SH must be defined in the absence of hypothalamic or pituitary disease and nonthyroidal illness (1) (B).

\section{Determination of etiology}

Primary overt hypothyroidism $(\mathrm{OH})$ refers to reduced thyroid hormone production, which causes an increase in TSH levels. Decreased thyroid secretion can also be a result of reduced stimulation of the thyroid gland due to decreased thyrotropin-releasing hormone (TRH) or TSH action. Hypothyroidism can also be explained by a reduced action of thyroid hormones in target organs, as in the rare cases of thyroid hormone resistance (2) (D).
The most frequent cause of primary hypothyroidism is chronic autoimmune thyroiditis (Hashimoto's thyroiditis). However it can also result from the treatment of hyperthyroidism with surgery, antithyroid drugs or 131I irradiation. Several forms of thyroiditis, including postpartum, silent, subacute or cytokine-induced thyroiditis can also cause permanent or transitory hypothyroidism. Less frequently, it can be a consequence of infiltrative or infectious disease, external radiation, thyroid dysgenesis, functional defects in thyroid hormone biosynthesis and release, and congenital defects in thyroid hormone biosynthesis. Iodine deficiency and iodine excess are well recognized causes of primary hypothyroidism, as are also the use of certain drugs that include antithyroid agents: lithium, natural and synthetic goitrogenic chemicals, tyrosine kinase inhibitors, interleukin-2 or interferon- $\alpha$ (IFN- $\alpha$ ) etc. SH shares the same etiology as overt primary hypothyroidism.

High serum TSH levels can often be the result of inadequate replacement therapy with levothyroxine due to poor compliance, drug interactions, lack of appropriate waiting time for the determination of TSH, both from the beginning of the treatment ( 3 months are required) or from change of dose or between commercial brands of levothyroxine (L-T4) (2 months are required) (3) (D), or from changes in the course of the disease.

Central hypothyroidism has multiple causes (tumors, trauma, vascular, infections, infiltrative, inflammatory or congenital). Apart from loss of functional tissue, central hypothyroidism can also result from functional defects in TSH biosynthesis or release due to both mutations and from drugs such as dopamine and glucocorticoids.

Peripheral hypothyroidism can be a consequence of mutations in genes that intervene in the thyroid response in target tissues (thyroid hormone resistance), or even more rarely be due to thyroid hormone consumption in massive infantile hemangioma (2) (D).

There are certain situations that have to be considered in the differential diagnosis of true hypothyroidism. In the assessment of TSH, some preanalytical (circadian rhythm, aging) or analytical variables (assay variability, abnormal TSH isoforms, or heterophilic antibodies) can contribute to high TSH levels. Other situations for misdiagnosis include the recovery from nonthyroidal illness, the period after withdrawal of levothyroxine in euthyroid patients, TSH-secreting pituitary adenoma, high TSH levels with lower biological 
action, isolated pituitary resistance to thyroid hormone, higher TSH values reported in obesity, and adrenal insufficiency (4) (D).

\section{Iodine deficiency in Latin America}

As a result of the recognition of iodine deficiency as the principal etiology for goiter worldwide, in the 1940s, several countries in Latin America started introducing the use of iodized salt in order to eliminate the goiter belts. Having recognized this disease as a public health problem, the World Health Organization (WHO) created a study group on endemic goiter, with the collaboration of John Stanbury and other prestigious Latin American experts to assure a permanent surveillance on iodine nutrition and thyroid function. This decision resulted in positive steps taken to prevent the development of goiter, such as in Argentina, where the national law on salt iodization was finally passed in 1967 (5) (D). In 1980, all the consequences of the lack of iodine, ranging from goiter to mental retardation, were gathered under the term "iodine deficiency disorders" (IDDs) and the measurement of urinary iodine concentration (UIC) levels became the best tool to monitor population iodine deficiency status (6) (D). In 1994, in an attempt to reduce the prevalence of iodine deficiency worldwide, the WHO recommended eliminating IDDs by iodizing all salt for human consumption $(6)(\mathbf{D})$. The prevalence of goiter as it relates to iodine nutrition has been more recently studied in school children from 13 Latin American countries with the use of the ThyroMobil model. In some of the regions, the prevalence was very low $(3.1 \%)$, while in others it reached $25 \%$, with median UIC correlating well with the iodine in the salt. The median iodine content in the salt varied outside the recommended range of 20-40 parts per million (ppm), but was greater than $78 \mathrm{ppm}$ in $83.1 \%$ of all samples, demonstrating a great achievement in the elimination of iodine deficiency in most of the studied countries (7) (B). From 2005 on, the WHO determined that each country should make its own reports on the iodine deficiency situation every 3 years. By 2007, the number of countries with iodine deficiency (median UIC $<100 \mu \mathrm{g} / \mathrm{l}$ ) had reduced from 54 in 2003 to 47 . Nevertheless, underexposure to iodine is still an issue (as is overexposure) (8) (B).

\section{Biochemical evaluation}

Serum TSH is the first-line diagnostic test for primary hypothyroidism. This is due to the inverse log-linear relationship between the concentrations of TSH and free $\mathrm{T} 4$, which determines that small linear decreases in free $\mathrm{T} 4$ concentrations are associated with an exponential increase in TSH concentrations (9) (B). Additionally, the TSH assay is accurate, widely available, safe and relatively inexpensive. Third-generation TSH immunometric assays (IA) have very high sensitivity and specificity $(10,11)(B, D)$.

TSH determination is essential for the diagnosis of hypothyroidism because clinical symptoms are not specific. There is no pathognomonic sign to clearly distinguish a patient with hypothyroidism. The association of bradycardia with delayed ankle reflex and coarse and dry skin presents a positive likelihood ratio (the likelihood ratio - + LR - that a given test result would be expected in a patient with the target disorder compared to the likelihood that the same result would be expected in a patient without that disorder) of only $3.75(+\mathrm{LR}=3.75,95 \%$ CI 1.65-8.52) $(12,13)$ $(\mathbf{B}, \mathbf{B})(14)(\mathbf{C})$, increasing the diagnosis (calculated as from $2 \%$ (pre-test disease prevalence) to $5 \%$ in overt hypothyroidism $(\mathrm{OH})$ and from $10 \%$ (pre-test disease prevalence) to $25 \%$ in subclinical hypothyroidism (SH) (15) (B). Table 1 lists symptoms with the best positive likelihood ratios for clinical diagnosis of hypothyroidism (16) (B).

Diagnostic accuracy is based on the comparison of a diagnostic test with its gold standard. However, for hypothyroidism, no gold standard is available. Although the introduction of ultrasensitive TSH tests has improved the study of thyroid disease, in hyperthyroidism in particular, estimating the diagnostic accuracy of TSH for the detection of hypothyroidism still has its limitations.

In ambulatory patients, $89 \%$ sensitivity and $95 \%$ specificity have been reported for TSH by immunoradiometric assay (IRMA). Taking into consideration these figures, the probability of detecting clinical hypothyroidism increases from $2 \%$ (pre-test disease prevalence) to $27 \%$. With regards to subclinical hypothyroidism, the probability of disease detection increases from $10 \%$ (pre-test disease prevalence) to $66 \%$ (17) (B). Similar results have been obtained with the use of immunochemiluminometric assays (ICMA), with $76.9 \%$ sensitivity and $96 \%$ specificity, increasing the diagnostic accuracy from $2 \%$ to $28 \%$ in clinical hypothyroidism and from $10 \%$ to $68 \%$ in $\mathrm{SH}(15)(\mathrm{B})$. No statistically significant differences between IRMA or ICMA methods have been detected (15) (B). 
Table 1. Symptoms of hypothyroidism and correlation for diagnosis

\begin{tabular}{lcc}
\hline Symptom & Frequency (\%) & $\begin{array}{c}\text { Likelihood Ratio (+ LR) } \\
\text { (95\% Confidence interval) }\end{array}$ \\
\hline Deeper voice & 14 & $7.1(2.0-24.7)$ \\
Hoarse voice & 21 & $5.2(2.1-12.6)$ \\
Puffy eyes & 36 & $4.0(2.2-7.3)$ \\
Constipation & 20 & $3.6(1.6-8.1)$ \\
Coldness & 39 & $3.5(2.0-6.0)$ \\
Poor memory & 39 & $2.6(1.6-4.2)$ \\
\hline
\end{tabular}

Clinical symptoms [adapted from reference 16 (B)].

With regards to the determination of isolated free T4 in ambulatory patients, sensitivity and specificity have been estimated at $82 \%$ and $94 \%$ respectively, increasing the probability of disease detection to $22 \%$ in overt hypothyroidism and to $60 \%$ in $\mathrm{SH}$. The association of both TSH and free T4 increases the diagnostic accuracy for overt hypothyroidism from $28 \%$ to $84 \%$ (ICMA) and from $27 \%$ to $83 \%$ (IRMA). For SH however, given its higher prevalence, there is an increase in diagnostic accuracy with both tests, from $68 \%$ to 97\% (ICMA) and from 66\% to 96\% (IRMA) (17) (B) (Table 2).

In hospitalized patients, a special situation presented itself $(18,19)(\mathbf{B})$. The use of drugs such as dopamine or glucorticoids that reduce TSH serum levels or other drugs that interfere with levothyroxine absorption, together with the lack of correct administration of levothyroxine and the presence of nonthyroidal disease (NTI), all explain why thyroid function testing in the admitted patient is often hampered. Free T4 testing becomes less reliable during hospitalization, especially in the critically ill patient $(20)$ (D).

With a TSH cutoff level of above $10 \mathrm{mU} / \mathrm{L}$, the probability of disease detection increases from $2 \%$ (pre- test disease prevalence) to $34 \% .(+\mathrm{LR}=24.75 ; 95 \% \mathrm{CI}$ 9.47-64.67) (21) (B). If serum TSH is within normal range, it is very difficult to sustain the diagnosis of hypothyroidism unless a hypothalamic-pituitary cause is involved. However, in those cases, clinical manifestations will prevail. If TSH levels are high but free T4 levels are normal, unless there is a nonthyroidal illness syndrome present, it most probably indicates $\mathrm{SH}(22)(\mathbf{D})$.

As stated above, the reason for maintaining circulating T4 values within the reference range in $\mathrm{SH}$ is the high sensitivity of the pituitary thyrotroph for even very small decreases of serum T4. The best method to assess free T4 is ultrafiltration or dialysis equilibrium/liquid chromatography - tandem mass spectrometry (UF/ DE/LC-MS/MS) which display a stronger log/linear relationship with TSH compared with immunoassay (IA) methods (23) (B), however, for practical reasons, free T4 has to rely on IA methods that "estimate" its serum levels.

Some authors have proposed dividing $\mathrm{SH}$ into a mild form (serum TSH concentrations of 4.5-9 mU/L) and a severe form ( $\mathrm{TSH} \geq 10 \mathrm{mU} / \mathrm{L}$ ) in regards to its respective clinical consequences (24) (D).

\section{Analysis of the upper limit of normal range TSH values according to age and specific populations}

The normal range of TSH values in thyroid disease-free individuals has been traditionally accepted as $0.45-4.5$ $\mathrm{mU} / \mathrm{L}$. This corresponds to 2.5 th to 97.5 th percentile of the distribution curve of TSH in most populations. This reference range is considered as "experimental" or population based $(22,24)(\mathbf{D}, \mathbf{D})$. This concept is based on epidemiologic studies such as the National Health and Nutritional Examination Survey (NHANES) III, where the reference range for TSH concentration was found to be $0.45-4.12 \mathrm{mU} / \mathrm{l}$, with a median value of $1.4 \mathrm{mU} / \mathrm{L}(25)(\mathbf{B})$.

Table 2. Diagnosis of overt hypothyroidism $(\mathrm{OH})$ and subclinical hypothyroidism $(\mathrm{SH})$ in ambulatory patients

\begin{tabular}{|c|c|c|c|c|c|}
\hline & \multirow{2}{*}{ Sensitivity \% } & \multirow{2}{*}{ Specificity \% } & \multirow{2}{*}{ +LR (95\% Cl) } & \multicolumn{2}{|c|}{ Diagnosis $\mathrm{OF}$} \\
\hline & & & & $\mathrm{OH}$ & SH \\
\hline TSH (ICMA) & 76.9 & 96 & $19.19(7.30-50.44)$ & $2 \% \uparrow 28 \%$ & $10 \% \uparrow 68 \%$ \\
\hline TSH (IRMA) & 89 & 95 & $17.80(7.55-41.94)$ & $2 \% \uparrow 27 \%$ & $10 \% \uparrow 66 \%$ \\
\hline Free T4 & 82 & 94 & $13.67(6.26-29.85)$ & $2 \% \uparrow 22 \%$ & $10 \% \uparrow 60 \%$ \\
\hline TSH + Free T4 (ICMA) & & & & $28 \% \uparrow 84 \%$ & $68 \% \uparrow 97 \%$ \\
\hline TSH + Free T4 (IRMA) & & & & $27 \% \uparrow 83 \%$ & $66 \% \uparrow 96 \%$ \\
\hline
\end{tabular}

Adapted from reference 17 (B). Positive likelihood ratio (+LR). 
Since TSH values do not have a Gaussian distribution, (25) (A) other TSH cutoff values have been proposed, based on the notion that $95 \%$ of the normal population has TSH values below $2.5 \mathrm{mU} / \mathrm{L}(22)(\mathrm{D})$. However, this idea has been controversial except for in pregnancy (see pregnancy section). Another important issue to be considered is that all thyroid tests have a narrow within-person variability relative to the population reference range (that is, thyroid tests have a low index of individuality). Population reference range is not an individual's normal range, so before a test moves outside the population reference range, a considerable degree of abnormality is required. (26) (B).

An "empirical" reference range between 0.3 and 3.0 $\mathrm{mU} / \mathrm{L}$ (American Association of Clinical Endocrinologists and National Academy of Clinical Biochemistry) $(22,27)(\mathbf{D}, \mathbf{D})$ has been also proposed as an alternative to the "experimental" (population based) reference range, due to the large number of factors affecting the upper limits in all population studies, (including individual and geographic variables).

The upper limit of TSH values may increase with age, as shown in the NHANES III population. In fact, if TSH upper level remains at $4.5 \mathrm{mU} / \mathrm{L}, 74 \%$ of TSH values of elderly patients aged 80 years or older without TPOAb positive values would be found to be above this level (28) (A). According to a reanalysis of the NHANES III TSH distribution curves in TPOAb negative individuals between 50-59 years, TSH upper levels would correspond to $4.2 \mathrm{mU} / \mathrm{L}$, between 60-69 years, to $4.7 \mathrm{mU} / \mathrm{L}$, between $70-79$ years, to $5.6 \mathrm{mU} / \mathrm{L}$, and in subjects over age 80, to $6.3 \mathrm{mU} / \mathrm{L}(29)(\mathrm{A})$.

In critically ill patients in whom transient fluctuations in TSH are common, a wider TSH reference range, about 0.05 to $10 \mathrm{mU} / \mathrm{L}$, is recommended for diagnosis of hypothyroidism (22) (D).

Repeat TSH testing is important to rule out transient TSH increases, intraindividual variability or biochemical errors. Between the range of 4.5 and 10 $\mathrm{mU} / \mathrm{L}$, the possibility of return of TSH to normal serum levels is high (30) (B). It has been proposed that 2-3 months after the initial TSH determination, a second assay should be performed to confirm the thyroid deficiency $(22,31)(\mathbf{D}, \mathbf{D})$. The chances of finding transitory elevations of TSH are minimized, as higher TSH values are found or in patients who are TPOAb or TgAb positive (32) (A).

\section{Prevalence}

While the prevalence of $\mathrm{OH}$ has been reported at 1.5\%, $\mathrm{SH}$ is nearly ten-fold more frequent. Its prevalence differs according to studies from between 6-20\%, depending on age, sex, race, iodine repletion of the population studied, as well as the TSH cutoff level employed to define $\mathrm{SH}(25,33-35)(\mathbf{A})$.

\section{HOW TO MAKE THE DIAGNOSIS OF HYPOTHYROIDISM?}

The diagnosis of hypothyroidism is often not so evident. It is an endocrinological disorder that requires a high index of suspicion in disparate clinical scenarios that span from the critically ill lethargic patient with anasarca to the dyslipidemic postmenopausal woman who consults for obesity. To determine if hypothyroidism is present, physicians must be alert to detect the most frequent signs and symptoms of overt hypothyroidism such as bradycardia, delayed ankle reflex, coarse and dry skin, weakness, lethargy, slow speech, edema of eyelids, sensation of cold, decreased sweating, cold skin, macroglosia, facial edema, coarseness of hair, cardiac enlargement (on x-ray), pallor of skin, impaired memory, constipation, weight gain, hair loss, dyspnea, peripheral edema, hoarseness, anorexia, nervousness, menorrhagia, deafness, palpitations, poor heart sounds, precordial pain, and poor vision, among many others (36) (C). Based on the predictive value of these signs and symptoms, several clinical composite scores have been developed to measure the degree of hypothyroi$\operatorname{dism}(37,38)(\mathbf{B}, \mathbf{D})$.

Unfortunately, many of these clinical features are nonspecific, especially in elderly patients (39-41) (D), nor are frequent in $\mathrm{SH}$. Therefore, some risk factors, listed in table 2, might raise a suspicion and prompt an evaluation for hypothyroidism.

Once the clinical aspects have been evaluated, a biochemical assessment will follow in order to diagnose or rule out hypothyroidism. If $\mathrm{OH}$ is suspected, TSH and free T4 should be determined $(22,31)(\mathbf{D})$.

The next step following confirmation of hypothyroidism is to ascertain its etiology. The family and personal history, the presence of goiter and TPO antibodies will help in this task $(22,31)(\mathbf{D})$. For SH, initial strategies include several possibilities (42) (D): the assessment of isolated TSH, which has higher sensitivity than isolated free T4 due to the log-linear 
relationship between them; TSH + TPOAb and TSH + free T4. The combination TSH + estimated free T4 is ideal, because TSH alone cannot detect patients with central hypothyroidism, and may lead to misdiagnosis when the thyroid state is unstable at the beginning of the treatment with LT4. Moreover, this last approach has the advantage of permitting the clinical validation of the relationship of TSH to free T4 to detect method interference or clinical discrepancies in less common conditions. However, it has to be considered that free T4 levels do not result from a direct measurement of free hormone; they are an estimation of free T4 levels. Therefore, assessing free T4 has its own technical limitations, yielding false results, especially when there are alterations of binding protein. In the context of nonthyroidal disease (NTI), when albumin is abnormal, affecting free T4 analog based immunoassays, or when the patient receives drugs that displace $\mathrm{T} 4$ from the $\mathrm{TBG}$, such as phenytoin, carbamazepine, or furosemide, TSH + total $\mathrm{T} 4$ should be determined.

It must also be considered that in certain, situations such as at the onset of hypothyroidism and during treatment of hyperthyroidism, discordance may occur between the plasma thyroid hormone concentrations and the TSH levels.

If a high TSH has been confirmed (either with or without low estimated free $\mathrm{T} 4$ or total $\mathrm{T} 4$ ), TPOAb measurement is a useful tool to establish that autoimmunity is the cause of hypothyroidism.

The initial pair TSH + TPOAb, on the other hand, has gained some popularity. Among the different reasons are the recognition that autoimmunity is associated with early elevations of TSH, improvements in the methods for determining autoantibodies that precede by years the development of autoimmune thyroid disease (AITD), and the weakness in current free T4 dosage. The knowledge that TPOAb precedes the development of clinical diagnosis of AITD by years, suggests that their presence in apparently healthy individuals should not be overlooked. (43) (C).

Finally, if the patient belongs to the risk group for $\mathrm{SH}$ (see Screening Section below), an initial TSH is required. If found elevated, 2-3 months later TSH + free $\mathrm{T} 4$ will be required to confirm the diagnosis. TPOAb assessment is also necessary to certify thyroid autoimmunity.

\section{Recommendation 1}

For the general population, we recommend using traditional TSH normal range values $(0.45-4.5 \mathrm{mU} / \mathrm{L})$. Grade A.

Higher cutoff TSH levels must be considered for elderly patients. Grade A.

\section{Recommendation 2}

Clinicians cannot vely exclusively on physical examination to confirm or rule out hypothyroidism. Patients with physical signs such as deeper voice $(L R+=7.1)$, hoarser voice $(L R+=5.2)$, puffy eyes $(L R+=4.0)$, bradycardia $(L R+=3.88)$, constipation $(L R+=3.6)$, coldness $(L R$ $+=3.5)$, delayed ankle reflex $(L R+=3.4)$, poor memory $(L R+=2.6)$, coarse skin $(L R+=2.3)$, puffy face $(L R+$ $=1.15)$, pretibial edema $(L R+=1.13)$ and slow movements $(L R+=1)$ are suspected of hypothyroidism and require a diagnostic workup that includes thyroid hormone assays. Grade B.

If the patient has clinical findings or a high probability of overt hypothyroidism, the measurement of both TSH and free $T 4$ are required. However, one must take into account that clinical findings of hypothyroidism are very unspecific. Grade D.

TPOAb determination is also recommended to confirm the presence of thyroid autoimmunity in primary bypothyroidism. Grade C.

\section{Recommendation 3}

To rule out SH when the patient belongs to any of the rish groups (described below in Screening Section Table 3), an initial TSH determination is suggested. If elevated, a repeat test adding free T4 should be performed 2-3 months later to confirm the diagnosis. TPOAb determination is also suggested to define the presence of thyroid autoimmunity. Grade D.

\section{WHO SHOULD BE SCREENED FOR HYPOTHYROIDISM?}

Screening can be defined as "the application of a test to detect a potential disease or condition in a person who has no known signs or symptoms of that condition at the time the test is done" (44) (D). In case-finding, testing for thyroid dysfunction is performed among patients who visit their clinicians for unrelated reasons. 
Until the benefit of treatment is confirmed, general population screening is not advisable for the detection of SH (45) (B).

The recommendations for screening differ substantially among professional societies and expert panels. However, case finding among high risk groups has been advocated, especially in pregnant women and in women who want to become pregnant.

\section{Management strategies}

\section{Guidelines for early detection and treatment (Table 3)}

Several guidelines for subclinical thyroid dysfunction have been published and they all have different screening recommendations. The American College of Physicians (in 1990 and 1998) recommended screening women older than 50 years of age for unsuspected but symptomatic thyroid disease. The goal of routine testing was to find overt, but overlooked, thyroid dysfunction, not SH (46) (D). Similarly, in 1999, the American Association of Clinical Endocrinologists (AACE) recommended screening asymptomatic women over the age of 60 (47) (D).

In 2000, the American Thyroid Association (ATA), using a consensus process to develop guidelines, recommended screening for all patients over 35 years of age every 5 years (more frequently if the patient was at increased risk) (48) (D). In 2003, the Institute of Medicine (IOM) and in 2004, the U.S. Preventive Services Task Force (USPSTF) examined the issue of screening for thyroid dysfunction among asymptomatic persons and the general population or in specific high-risk groups respectively, and both concluded that there is insufficient evidence to recommend periodic, routine screening for thyroid dysfunction using serum TSH levels (49) (B). The conclusions about the evidence were that the risk-benefit ratio of screening asymptomatic adults for thyroid disease could not be determined.

In 2004, a panel sponsored by AACE (47) (D), ATA (48) (D) and the Endocrine Society evaluated data regarding the management of subclinical thyroid dysfunction (24) (D). The panel used a systematic review of the evidence to arrive at its recommendations, and found insufficient evidence to support population -based screening and recommended against population-based screening for thyroid disease, though it did advocate aggressive case-finding in those considered high-risk, including pregnant women and women over $60(34)($ A).
Table 3. Clinical conditions to be considered for thyroid testing

Women of fertile age upwards, especially over 60 years

Pregnant women

Previous radiation treatment of the thyroid gland (radioactive iodine or therapeutic external beam radiation)

Previous thyroid surgery or thyroid dysfunction

Type 1 diabetes mellitus

Personal history of autoimmune disease (Vitiligo, Sjögren's syndrome, systemic lupus erythematosus, rheumatoid arthritis)

Down's syndrome

Turner syndrome

Family history of thyroid disease

Presence of goiter and/or TPOAb positivity

Clinical symptoms of hypothyroidism

Drugs such as lithium, amiodarone, interferon alpha, sunitinib and sorafenib

Hyperprolactinemia

Dyslipemia

Anemia

Heart failure

Besides the aforementioned group of women over 60 and pregnant women, the high-risk group for detection of $\mathrm{SH}$ also includes the following situations: individuals with previous radiation treatment of the thyroid gland (radioactive iodine or therapeutic external beam radiation), previous thyroid surgery or thyroid dysfunction (32) (A), Type 1 diabetes mellitus, personal history of autoimmune disease, or a family history of thyroid disease, presence of goiter, TPOAb positivity, clinical symptoms of hypothyroidism, hyperprolactinemia, dyslipemia, or use of certain drugs such as lithium, amiodarone and interferon alpha (24) (D).

\section{What is the importance of family history of autoimmunity or other organ-specific autoimmune diseases?}

Autoimmune disorders can be divided into organ-specific and non-organ-specific (or systemic) disorders. Autoimmune thyroid diseases (AITD), and Type 1 diabetes mellitus (TIDM) are considered organ-specific diseases. On the other hand, connective tissue diseases such as systemic lupus erythematosus (SLE) and primary Sjögren's syndrome (pSS) are characterized by nonspecific systemic inflammation. 


\section{AITD}

The presence of AITD among patients with systemic autoimmune diseases has been well recognized. Moreover, other autoantibodies associated with systemic autoimmune diseases have been detected in patients with AITD. Antinuclear antibodies (ANA) are detected in $1 / 3$ of patients with AITD, a higher prevalence in comparison with healthy controls (50) (B).

The autoantibody profile in AITD and the distribution of thyroid-related autoantibodies in other autoimmune disorders have been also evaluated (51) (B). Thyroid related autoantibodies were significantly elevated in all autoimmune diseases analyzed (DMl, primary biliary cirrhosis, autoimmune hepatitis, SLE, pSS and myasthenia gravis), suggesting a close relationship between AITD and other immune-mediated diseases.

The etiology of AITD is multifactorial. Genetics play an important role in the development of AITD. Many patients have family members also affected by this condition. The inheritance of AITD is polygenetic and only a few of the susceptibility genes have been identified to date $(52,53)(\mathbf{B}, \mathbf{B})$. A large prospective cohort study of subjects at risk of developing AITD (healthy female relatives of AITD patients) was conducted. Only first or second-degree female relatives of patients with documented AITD were included. With a follow up of 5 years, of the 803 subjects seen at baseline, 29 (3.6\%) were found to be hypothyroid, 10 of whom had overt disease (1.3\%). Risk factors for hypothyroidism were advanced age, and the strongest factor was the presence of TPOAb. Of the 759 participants with normal thyroid function, in $183(24 \%)$, TPOAb was also positive. In this group, the presence of TPOAb was associated with age and pregnancy and correlated significantly with TSH levels. The authors detected only age and TPOAb as factors that increased the risk for hypothyroidism. Despite some limitations, this study strongly supports the importance of genetic factors in the development of autoimmune thyroid disease in view of the high prevalence at baseline of autoimmune thyroiditis in this large group of subjects with a positive family history $(54)(\mathbf{A})$.

\section{Diabetes Type 1}

The combination of AITD and Type 1 diabetes is the most frequent among the autoimmune diseases and it is included as part of the polyglandular autoimmune syndrome (55) (B). Perros and cols. (56) (B) repor- ted thyroid dysfunction in up to $31.4 \%$ of adult Type 1 diabetic females. In children with Type 1 diabetes, $20 \%$ were found to be TPOAb positive and about 3-8\% developed hypothyroidism (57) (B). Moreover, postpartum thyroiditis is threefold higher (up to $25 \%$ ) in women with Type 1 diabetes (58) (A). With regards to screening, a retrospective study (59) (B) in a large population of diabetic patients showed that incident hypothyroidism was associated with baseline TSH concentration greater than $2.2 \mathrm{mU} / \mathrm{L}$, so this cutoff TSH level has been proposed for selective annual thyroid screening in diabetics.

\section{Primary Sjögren's syndrome (pSS)}

The first descriptions of the prevalence of pSS and AITD in the same subject (60-62) (C,B,B), showed that both conditions were associated in as few as 10 $21 \%$ of the cases, leading to the conclusion that AITD was rather uncommon in pSS. These results are at variance with other reports $(63,64)(\mathrm{D}, \mathrm{B})$ where AITD occurred in $37-50 \%$ of the patients. However, the absence of controls is a limitation that questions the validity of such significant results.

There are, however, a few studies with a comparison between case and controls and with good follow-up that confirm that thyroid disorders are more common in pSS than in controls (65-67) $(\mathbf{B}, \mathbf{B}, \mathbf{C})$.

\section{Rheumatoid arthritis (RA) and systemic lupus erythematosus (SLE)}

Regarding the prevalence of $\mathrm{SH}$ and its correlation with insulin resistance and other cardiovascular $(\mathrm{CV})$ risk factors in RA, Dessein and cols. (68) (B) described $12 \%$ of patients with clinical hypothyroidism who were taking thyroxine and $11 \%$ with $\mathrm{SH}$. Similar results were found by other authors $(69,70)(\mathbf{B}, \mathbf{B})$. They showed a significantly increased prevalence of thyroid disorders in SLE patients when compared to RA patients. In the two series, nearly $20 \%$ and $10 \%$ had hypothyroidism in the SLE and RA groups, respectively. TPOAb was found in 15\% of SLE and 5\% of RA patients and in $10 \%$ of controls, but the levels of TPOAb were higher in SLE and RA patients. They finally concluded that thyroid abnormalities were more frequent in SLE and RA patients. Therefore, determination of thyroid function tests in patients with SLE and RA as a part of the biochemical and immunological profiles may help in early detection of associated thyroid disorders. 


\section{Vitiligo}

Thyroid functional disorders and AITD have been reported in association with vitiligo. TPOAb was detected in $18.1 \%$ of patients affected by vitiligo, while it was $7.3 \%$ in the control group. When analyzing subgroups, the difference in the frequency of TPOAb remained significant only in females and in patients in the age range of 18-25. A periodic follow-up of vitiligo patients for detecting thyroid diseases is further emphasized, especially in young women with increased levels of TPOAb (71) $(\mathbf{C})$.

Hegedus and cols. found 6\% hypothyroidism and $25.8 \%$ with thyroid autoantibodies in patients with vitiligo (72) (B). More recently, a 40\% prevalence of thyroid disease was described in vitiligo patients. The risk is exacerbated in patients with thyroid autoimmunity, emphasizing the need for regular screening of vitiligo patients for AITD (73) (B).

\section{What is the importance of genetic diseases such as Down's syndrome and Turner's syndrome?}

\section{Down's syndrome (DS)}

It is well recognized that thyroid dysfunction occurs more frequently in DS than in the general population. Prevalence figures for hypothyroidism in DS will vary not only according to the age of the population tested, but also to the type and extent of thyroid dysfunction measured.

A community study of patients with DS between 5-21 years found elevated TSH concentrations in 7\% of participants (74) (B). Similar results were reported in a survey of 160 adults with DS with prevalences of decompensated and compensated hypothyroidism of $8.1 \%$ and $11.9 \%$, respectively $(75)(\mathbf{B})$.

More recently, a total of 50 DS patients were recruited and compared with a control group of 212 healthy adults. $\mathrm{SH}$ and TSH alterations were more frequent in the DS group $(\mathrm{p}=0.008)$. TPOAb was positive in $26 \%$. The prevalence of thyroid dysfunction was $18 \%$ in DS patients. Thyroid function testing should be performed periodically and treatment must be considered to prevent further neurocognitive alteration $(76)(\mathbf{B})$.

Clinical diagnosis is difficult in DS. The hypothyroid features can be masked by the phenotypic appearance, and symptoms such as weight gain, poor growth, and loss of access to affect might be attributed to the syndrome itself. Given these difficulties and the increased prevalence of hypothyroidism in DS, regular screening has been recommended $(75,77)(\mathbf{B}, \mathbf{B})$.

With regards to the evolution of thyroid function in adults with DS, limited long-term follow-up data is available. One study investigated annual thyroid function tests in 200 adults with DS over a 15 -year period and found that the 15-year incidence for clinical hypothyroidism remains low. The authors recommended that the routine screening for adults with DS who are euthyroid can be reduced to every 5 years rather than every 1-2 years, as has been previously recommended (75) (B).

\section{Turner syndrome (TS)}

Individuals with (TS) are prone to develop autoimmune conditions such as celiac disease (CD), AITD and TIDM. The described prevalence of hypothyroidism in girls with TS ranges from $0 \%$ to $40 \%$. Some authors related the prevalence of hypothyroidism in $24 \%$ and positive antibodies in $42 \%$ in a group of patients with a mean period of observation of $8.4 \pm 4.4$ years $(78)(\mathbf{B})$. Similar results were found by Fukuda and cols. (79) (B) who described that more than half of Japanese women with TS in adulthood had thyroid autoantibodies. In women with TS, monitoring of thyroid hormone is important to detect hypothyroidism earlier and start adequate replacement therapy.

In 2009, Mortensen and cols. (80) (A) examined the TS of various karyotypes for autoantibodies and corresponding diseases in a prospective cross-sectional study of the Danish population. TPOAb was present in $45 \%$ of patients, of whom $33 \%$ were hypothyroid. TS girls and women had a high predisposition to hypothyroidism and celiac disease.

Likewise, a Brazilian study (81) (B) evaluated 71 girls with TS in order to determine the prevalence of AITD among them, and to look for an association with age and karyotype. They found $15.5 \%, 23.9 \%$ and $33.8 \%$ with hypothyroidism, positive antithyroid antibodies and goiter, respectively. There were no significant differences in thyroid findings among patients with a $45, \mathrm{X}$ karyotype, mosaics, and structural rearrangements. Half of the patients exhibited one or more abnormalities, which demonstrates the importance of careful evaluation of thyroid function in all girls with TS.

Even though a high prevalence of AITD has been described in TS, the extent of this association is controversial as regards the prevalence of thyroid autoanti- 
body and the clinical impact of thyroid dysfunction. In a review of 75 unselected TS patients (age range 3-30 years) for thyroid disease and thyroid autoantibodies, 10 of $75(13.3 \%)$ TS patients had AITD. The prevalence of AITD increased significantly from the first (15\%) to the third $(30 \%)$ decade of life. Clinical AITD was diagnosed in $46 \%$ of TS patients with TPOAb and/or $\mathrm{TgAb}$. They concluded that TS patients are at higher than average risk of developing AITD not only in adolescence and adulthood, but also in childhood. Hypothyroidism, mainly subclinical, is the most frequent thyroid dysfunction (82) (B).

\section{Other situations where screening should be considered}

\section{Anemia}

Although the deficit of thyroid hormones can lead to anemia, on the other hand, patients with certain types of anemia can be more susceptible to hypothyroidism and benefit from screening for thyroid dysfunction. $\beta$-thalassemia major can be complicated with hypothyroidism due to regular transfusion therapy that leads to iron overload of the thyroid gland. A study in a pediatric cohort of $50 \beta$-thalassemia major patients showed that the prevalence of overt hypothyroidism was $8.4 \%$ at baseline and increased to $13.9 \%$ after 12 years of follow-up. In $25 \%$ of the patients, the degree of thyroid dysfunction worsened with varying degrees of severity. Five $(28 \%)$ of 17 patients with normal thyroid function at the beginning were classified as having subclinical hypothyroidism at the end of the study (83) (B).

Pernicious anemia, probably due to a common autoimmune origin, is another type of anemia related to primary hypothyroidism that has to be considered for thyroid screening (84) (B).

Another situation that might be considered for screening would be elderly patients with anemia. In a study of 316 patients aged 65 and older, hypothyroidism was found at a significantly higher incidence in those with anemia in comparison with those without anemia $(20$ vs. $9.9 \%, \mathrm{p}=0.01)(85)(\mathbf{B})$.

\section{Hyperprolactinemia}

The association between hyperprolactinemia and hypothyroidism is well known. In a prospective Brazilian study of 1,234 patients with various etiologies of hyper- prolactinemia, $6.3 \%$ presented primary hypothyroidism (86) (B).

\section{Lithium}

Lithium is frequently used in the treatment of affective disorders, mainly bipolar disorder. This drug can impair thyroid hormone metabolism by various mechanisms. Subclinical and clinical hypothyroidism due to lithium are usually associated with circulating TPOAb but may occur in their absence (87) (D).

Bocchetta and cols studied a total of 116 patients on lithium treatment and followed them up for 2 years to determine the course and the clinical relevance of thyroid abnormalities. They found that the risk of developing hypothyroidism was higher in women, especially in the presence of TPOAb $(88)(\mathbf{B})$.

In a study that included 164 elderly patients with affective disorder, the prevalence of hypothyroidism (subclinical and clinical) was $35.4 \%$ among the lithium patients, women having a prevalence as high as $41.3 \%$ and men, $12.6 \%$. In the non-lithium patients, however, the prevalence was $7.1 \%$; similar to that in the general population (89) $($ B).

\section{Interferon- $\alpha$}

Patients treated with interferon- $\alpha$ (IFN $\alpha$ ) for Hepatitis $\mathrm{C}$ are at risk of hypothyroidism. In a prospective study where distinct types of IFN $\alpha 2$ were administered for 48 weeks, $16.7 \%$ of previously euthyroid patients developed abnormal TSH values during therapy, including 24 with TSH below $0.1 \mathrm{mU} /$ liter, 69 with TSH over $5.5 \mathrm{mU} /$ liter, and 76 with biphasic thyroiditis $(90)(\mathbf{B})$.

\section{Tyrosine kinase inhibitors}

An increased incidence of hypothyroidism (20-40\%) during treatment with sunitinib and sorafenib in metastatic renal cell carcinoma has been previously reported (91) (B).

\section{Amiodarone}

Amiodarone can induce hypothyroidism with varying frequency according to different geographical distribution. Prevalence of amiodarone-induced hypothyroidism in iodine sufficient areas has been reported between 13\% (92) (D) and 40\% (93) (A). However, in low iodine intake areas the incidence rate of hypo- 
thyroidism was found to be only $6 \%(94)(\mathbf{B})$. The mechanisms that could play a role in the development of amiodarone-induced hypothyroidism are the persistent Wolff-Chaikoff Effect (autoregulatory effect that blocks the synthesis and release of thyroid hormones from the gland), the preexistence of thyroid antibodies, higher baseline levels of thyroid-stimulating hormone, a positive family history of thyroid disease and residence in iodine-sufficient areas. Patients at high risk for amiodarone-induced hypothyroidism (such as women with preexisting thyroid antibodies) should be followed closely. Although thyroid dysfunction can develop at any time, in predisposed patients, it is usually an early phenomenon (92) (D).

Initial baseline thyroid function tests should be done in order to exclude underlying gland dysfunction that may predispose the patient to hyper- or hypothyroidism after amiodarone therapy is started. Serum levels of TSH and peripheral thyroid hormones may be assessed 3 months after amiodarone is started. Values obtained at this stage (normal TSH levels, slightly increased or normal thyroxine levels, and low normal triiodothyronine levels) may be considered reference values for subsequent comparisons. After the first 3 months, periodic monitoring of serum TSH levels alone may suffice as a screening test (95) (B).

In order to determine the frequency of screening subclinical thyroid disorders, Pazin-Filho and cols. (93) (A) evaluated 121 patients under long term treatment with amiodarone. Patients were followed for a median period of 3.2 years. Thyroid dysfunction was detected in $59(48.7 \%)$ of the 121 patients, amiodarone-induced hypothyroidism in 50 (41.3\%) and hyperthyroidism in $9(7.5 \%)$. The incidence rate for amiodarone-induced thyroid disease was 39.3 (95\% CI 9.2-61.9) cases per 1,000 patients/year during the first 6 months of follow-up. This data supports the need for screening at 6-month intervals.

\section{Dyslipemia}

Hypothyroidism is a recognized cause of secondary dyslipidemia and in any person who presents with elevated $\mathrm{LDL}$ cholesterol $(>160 \mathrm{mg} / \mathrm{dL}$ ), it has been recommended to test for hypothyroidism (96) (D). A recent prospective study in Japan reported that the prevalence of hypothyroidism was $4.3 \%$ in patients with hypercholesterolemia ( $1.4 \%$ with primary overt hypothyroidism, $2.3 \%$ with subclinical hypothyroi- dism, and 0.4\% with central hypothyroidism) (97) (B). These values are relatively similar to those of the general population, nevertheless, the early detection of hypothyroidism and its treatment with levothyroxine would avoid unnecessary life-long use of antilipemic agents in these patients.

\section{Depression}

With regards to depression, although it has been related to hypothyroidism, several studies have failed to find a consistent relationship between these two entities (98-100) (A). On the other hand, in positive TPOAb subjects, depression was found to be more frequent. Prevalence of a lifetime of depression was higher in subjects with positive TPOAb $(24.2 \%)$ in comparison to those without TPOAb $(16.7 \%)$, with a relative risk of 1.4 (95\% CI 1.0-2.1; p $=0.04$ after adjustment for confounders) (101) (B). Therefore the need to rule out hypothyroidism in a depressive patient is still an unresolved matter.

\section{Heart failure}

Hypothyroidism has detrimental effects on the cardiovascular system (102) (D). Therefore, in patients with heart failure, it is important to detect it and eventually treat it. With regards to $\mathrm{SH}$, it has also been recognized as an important risk factor for HF in older adults. A meta-analysis of six prospective cohort studies for a total of 2,068 patients with $\mathrm{SH}$, specifically with $\mathrm{TSH}>10 \mathrm{mU} / \mathrm{l}$, showed a higher risk of heart failure (103) (A). Therefore, heart failure patients would also be good candidates for whom hypothyroidism must be ruled out (104) (D).

\section{Recommendation 4}

Screening for hypothyroidism should be performed in women of fertile age and upwards, especially older than 60 years. Grade A.

Other population risk groups include persons with previous radiation treatment of the thyroid gland (radioactive iodine or therapentic external beam radiation), previous thyroid surgery, or thyroid dysfunction, TPOAb positivity, use of certain drugs such as amiodarone Grade A or lithium, TIDM, Sjögren's syndrome, systemic lupus erythematosus, rheumatoid arthritis, vitiligo, Down's syndrome, Turner syndrome, heart failure, dyslipemia, byperprolactinemia and anemia. Grade B. 
Screening for hypothyroidism should be performed in the presence of goiter and clinical features of hypothyroidism. Grade D.

Screening for hypothyroidism should be performed in patients with a family history of AITD considering the high prevalence of this association. Grade A.

\section{HOW SHOULD CASE FINDING BE DONE?}

As the majority of cases of hypothyroidism and hyperthyroidism encountered in general medical practice are caused by primary disease of the thyroid gland, TSH is ideal for biochemical testing.

Therefore, in the search for hypothyroidism, TSH should be the first-line test in patients with stable thyroid condition and intact hypothalamus-pituitary axes, and is more sensitive than estimated free T4. An initial TSH measurement alone in ambulatory patients has been proposed, followed by free T4 to distinguish between clinical and $\mathrm{SH}$, only if TSH is abnormal or if suspected abnormalities in its secretion (22) (D).

The appropriate time interval for retesting individuals with subclinical thyroid dysfunction is unknown. A recent British guideline offered the following typical strategy for active surveillance: If screening is performed, and a high serum TSH concentration and normal free T4 is found, repeat measurement 3-6 months later after excluding nonthyroidal illness and drug interference $(31)(\mathbf{D})$, while other authors supported that a high TSH should be confirmed with a second measurement performed 3 weeks apart, because laboratory reference ranges established from populations or adopted from guidelines tend to be wider than an intra-individual's range, which only varies $\pm 0.5 \mathrm{mU} / \mathrm{L}$ over time, so that a change between measurements of $0.75 \mathrm{mU} / \mathrm{L}$ would be considered significant (26) (B).

Other guidelines based in determining precision for functional sensitivity of TSH over 6-8 weeks suggest that this would probably be a reasonable time between measurements (22) (D).

It should be pointed out that thyroid function should be evaluated based on TSH and total T4 (and not estimated free T4) in the setting of hospitalized patients with severe nonthyroidal disease (NTI), when albumin is abnormal and affects free T4 analog based immunoassays (IA), or when the patient receives medications that displace T4 from the TBG, such as phenytoin, carbamazepine or furosemide. As previously mentioned, a broa- der TSH reference range, about 0.05 to $10 \mathrm{mU} / \mathrm{L}$ is used to screen for hypothyroidism (22) (D).

If hypothyroidism has been confirmed, TPOAb measurement should be used to determine etiology. If $\mathrm{SH}$ has been detected and observation is decided upon, TSH can be repeated annually in TPOAb positive patients, if negative, it can be repeated every 3 years (31) (D). There is no consensus on initially determining TPOAb in conjunction with TSH for screening, except in some particular situations such as pregnancy $(22)(\mathbf{D})$.

\section{Recommendation 5}

Case finding for hypothyroidism should be performed with TSH. If abnormal and confirmed after 2-3 months, free T4 should be done. Grade D.

If autoimmunity is suspected as the cause of hypothyroidism, ТРОAb should be also determined. Grade B.

Although thyroid function testing is not routinely recommended in hospitalized patients, if hypothyroidism has to be ruled out, an initial combination of TSH+T4+TPOAb should be performed in order to make a differential diagnosis with thyroid test alterations during nonthyroidal illness. Grade D.

What is the proportion of positive thyroid antibodies in the general population and what does it mean?

Estimates of TPOAb prevalence in the general population depend on the sensitivity and specificity of the method employed. Sensitivity of TgAb methods may be improved using the detection limit (analytical sensitivity ) instead of manufacturer-recommended cutoffs (105) (D). It is necessary to assess whether or not the same occurs with TPOAb, without loss of specificity.

A number of large-scale studies have established a high prevalence of TPO antibodies in normal euthyroid subjects. The NHANES survey of $\pm 17,000$ subjects without apparent thyroid disease, reported that TPOAb was detected in $12.6 \%$ of subjects using a competitive immunoassay method. Furthermore, hypothyroidism was strongly associated with the presence of TPOAb (and not $\mathrm{TgAb}$ alone) (25) (B), with a clear female preponderance $(2: 1)$ and with aging.

In recent studies, similar prevalence of positivity, $12.4 \%$ to $14 \%(35,43,106)(\mathrm{B} / \mathrm{C} / \mathrm{B})$ has been reported. Findings of longitudinal studies such as the 20 year follow up of the Whickham survey, suggest that even low levels of TPOAb may reflect occult thyroid dysfunction and are a risk factor for the development of 
clinical thyroid dysfunction over a timeframe of years or decades (107) (B).

Although the presence of TPOAb usually precedes the development of thyroid dysfunction, recent studies suggest that a hypoechoic ultrasound pattern may precede a biochemical TPOAb abnormality $(108,109)$ $(\mathbf{A}, \mathbf{B})$ The paradoxical absence of TPOAb in some patients with unequivocal TSH abnormalities likely reflects the suboptimal clinical and methodological sensitivity and/or specificity of current TPOAb tests (25, 109) $(\mathbf{B}, \mathbf{B})$.

There are two classes of TPOAb and TgAb immunoassay methods. Class 1 assays are characterized by a low detection limit and report undetectable $\mathrm{Ab}$ in normal subjects, suggesting that any $\mathrm{Ab}$ detected is pathologic. In contrast, Class 2 assays are characterized by higher detection limits and report a "normal range", consistent with the hypothesis that "natural" antibodies may circulate in normal individuals. These "normal" values may either represent non-specific assay "noise" or have clinical significance (110) (B).

Overall, although the significance of positive $A b$ in healthy individuals remains unclear, their presence in apparently healthy individuals should not be neglected, as they may serve as a useful tool to screen for future AITD phenotype (43) (C).

\section{When should anti-thyroid antibodies be measured?}

TPOAb are the hallmark of AITD and are present in almost all patients with Hashimoto's thyroiditis, with sensitivity and specificity of $91.9 \%$ and $92.7 \%$ respectively $(+\mathrm{LR}=13.0 ; 95 \% \mathrm{CI} 6.35-26.61)$. The probability of disease detection increases from $2 \%$ (pre-test disease prevalence) to $21 \%$ (111) (B), in two-thirds of patients with postpartum thyroiditis, with sensitivity and specificity of $86 \%$ and $94 \%$ respectively $(+\mathrm{LR}=14.3 ; 95 \% \mathrm{CI}$ 6.57-31.26), with increases from $22 \%$ (pre-test disease prevalence) to $80 \%(112,113)(\mathrm{A})$, and also in $75 \%$ of patients with Graves' disease (114) with sensitivity and specificity of $87 \%$ and $94 \%$ respectively $(+\mathrm{LR}=14.5$; 95\% CI 6.65-31.6) (B). The antibodies are mainly produced by a lymphocytic infiltrate in the thyroid gland, and only to a small extent by regional lymph nodes or in the bone marrow (115) (D).

Indeed, TPOAb levels reflect the severity of the lymphocytic infiltration, regardless of the presence or absence of hypothyroidism. Several groups found a significant correlation between the degree of lymphocytic infiltration and the titer of microsomal antibodies. In addition, an association exists between TPOAb titers and TSH levels in euthyroid subjects (54) (A). Therefore, TPOAb assay has been shown to be a sensitive and specific marker for thyroid autoimmune disease, with clearly better accuracy than TgAb.

TPOAb predicts the development of overt hypothyroidism in patients with SH. Thyroid antibodies should be measured for the diagnosis of AITD and should be considered a risk factor for development of thyroid dysfunction in subjects with other autoimmune disorders, and in patients using interferon, interleukin-2, lithium or amiodarone therapy (22) (D).

Although changes in autoantibody concentrations often reflect a change in disease activity, serial thyroid autoantibody measurements are not recommended for monitoring treatment for AITD. As was previously described, TPOAb prevalence is increased in patients with nonthyroidal autoimmune diseases. Aging is also associated with an increased prevalence of TPOAb in both SH and overt hypothyroidism (25) (B).

Considering that isolated positivity of $\operatorname{TgAb}$ may occur in approximately $10 \%$ of patients without proven thyroid disease, caution has been suggested in supporting simultaneous TPOAb and $\mathrm{TgAb}$ testing $(25,106)(\mathbf{B}, \mathbf{B})$. Isolated TgAb may also be observed in some cases of TPOAb negative AITD; this generally occurs in the initial phase of AITD and in patients showing normal or slightly raised TSH, and in areas with high iodine intakes (116) (B). Consequently, in normal iodine intake areas, $\mathrm{TgAb}$ testing does not add relevant information for patient management (117) (D).

\section{Recommendation 6}

For diagnosis of AITD, we recommend measuring TPOAb. If positive, it does not need to be repeated. Grade $B$.

In the risk groups for AITD, TPOAb determination is recommended. Grade $B$.

\section{WHEN SHOULD THYROID ULTRASONOGRAPHY BE PERFORMED?}

Thyroid ultrasonography (US) can show decreased echogenicity in both overt and subclinical hypothyroidism (108) (A). In autoimmune thyroiditis, the gland is typically enlarged, the parenchyma is heterogeneous, diffusely hypoechogenic, and often hypervascular (118) (B). The usefulness of US examination for the 
treatment approach of patients with hypothyroidism has been investigated.

In a cross-sectional investigation of 4,649 randomly selected adult subjects, hypoechogenicity and irregular echo pattern at thyroid US were significantly associated with higher levels of serum TSH, even in subjects without overt thyroid disease, suggesting a possible use of thyroid US in detecting early and subclinical thyroid dysfunction (108). (A). In the same study, the Odds Ratios for being TPOAb positive in patients with mildly and markedly decreased echogenicity were 5.0 (95\% CI 3.6-7.1) and 33.7 (95\% CI 5.5-97.9), respectively. Similarly, in another large multicenter study (109) (B) including 3,077 patients, the positive predictive value of reduced thyroid echogenicity as an indicator of autoimmune thyroiditis was $88.3 \%$, and the negative predictive value of this finding was $93 \%$. In 451 ambulatory patients with unknown thyroid status, the negative predictive value of normal US for detection of euthyroidism in TPOAb negative subjects was $91 \%$, and the positive predictive value of thyroid hypoechogenicity for detection of autoimmune thyroiditis was $85 \%$ and $87 \%$ with overt or any degree of hypothyroidism, respectively (119) (B).

Thyroid US has been also applied to identify patients with subclinical hypothyroidism who are prone to develop overt hypothyroidism. In a prospective study (120) (A) performed in 1184 consecutive ambulatory patients, thyroid function was normal in all patients with normal thyroid echogenicity, whereas hypothyroidism was found in $63.6 \%$ with hypoechogenicity. In this study, none of the patients with autoimmune thyroiditis and normal thyroid echogenicity became hypothyroid over an 18-month follow-up period. More recently, in a smaller prospective Latin American study among 117 women with subclinical hypothyroidism followed for a period of 3 years, the need for L-T4 was higher in the group with sonographic characteristics of autoimmune thyroiditis (121) (A). L-T4 requirement was similar between TPOAb-positive and TPOAb-negative patients as long as they exhibited US hypoechogenicity.

Altogether, these findings suggest that thyroid hypoechogenicity pattern is indicative of autoimmune thyroiditis and could be useful to identify the etiology of hypothyroidism in patients with negative thyroid antibodies. In addition, thyroid US could also be useful in identifying patients with subclinical hypothyroidism with a higher risk to develop overt hypothyroidism.
A micronodular pattern on thyroid US is also highly diagnostic of Hashimoto's thyroiditis (118) (B). Benign and malignant nodules can coexist, but whether thyroid US should be performed for all hypothyroid patients despite their thyroid palpation characteristics remains an unanswered question, because there is no cost-effective evidence for or against.

\section{Recommendation 7}

Routine thyroid US is not recommended in patients with either clinical or subclinical hypothyroidism. However, it should be considered for patients with negative thyroid antibodies to identify patients with autoimmune thyroiditis. Grade A.

Thyroid US can also be considered for those patients with subclinical bypothyroidism to belp in the evaluation of the risk of progression to overt hypothyroidism. Grade A.

The panel also recommends that thyroid US should be performed for patients with hypothyroidism and abnormal thyroid palpation. Grade D.

\section{WHICH PATIENTS WITH SUBCLINICAL HYPOTHYROIDISM SHOULD BE CONSIDERED FOR TREATMENT WITH THYROID HORMONES?}

Despite the elevated prevalence of $\mathrm{SH}$ in the general population, treatment remains controversial in clinical practice since there are no adequately powered randomized clinical trials (RCT) to detect the benefit of levothyroxine replacement therapy. Thus, the choice between treating and not treating patients with $\mathrm{SH}$ will depend mainly on the best clinical judgment. Clinicians should bear in mind the potential risks to the individual's health posed by not treating persistent SH. The likelihood of progression to overt hypothyroidism and the clinical significance of $\mathrm{SH}$, including impact on quality of life, cognitive function, cardiovascular risk, and life expectancy have to be carefully considered.

\section{What is the likelihood of progression to overt hypothyroidism?}

The risk of progression from SH to overt hypothyroidism is an important parameter to be considered before deciding to treat a patient with $\mathrm{SH}$. Patients at higher risk of progression to overt hypothyroidism (for example: patients treated with radioactive iodine or undergone thyroid surgery) would be natural candidates for early treatment aimed at preventing worse- 
Table 4. Sensitivity, specificity, positive predictive value (PPV) of baseline serum TSH $>2.5$ or $>4.0 \mathrm{mU} / \mathrm{L}$ for the presence of overt hypothyroidism (OH) and hypothyroidism $(\mathrm{H})$ at follow-up (13 years)

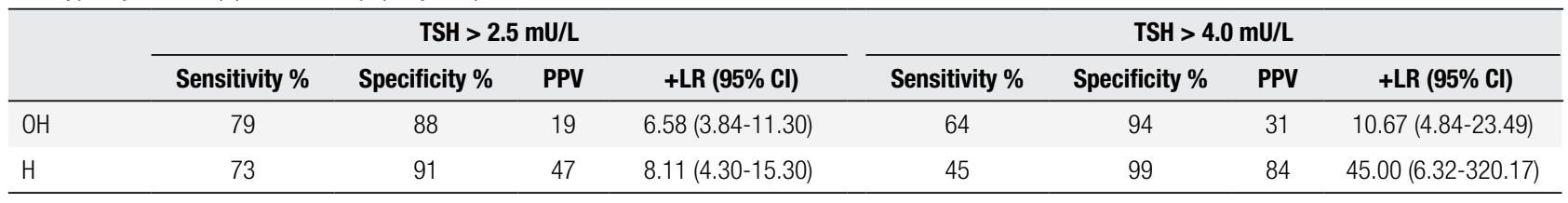

(Modified from reference 123 (A) where $\mathrm{H}$ is serum TSH greater than $4 \mathrm{mU} / \mathrm{L}$ or on treatment with $\mathrm{L}-\mathrm{T} 4$ and $\mathrm{OH}$ is defined by TSH greater than $10 \mathrm{mU} / \mathrm{L}$ or on $\mathrm{LT} 4$.)

ning of quality of life. After 9.2 years, $28 \%$ of patients developed overt hypothyroidism, with an annual progression rate of $\mathrm{SH}$ to $\mathrm{OH}$ of $11.4 \%$ (32) (A). However, before considering treatment, clinicians should verify if $\mathrm{SH}$ is persistent, since more than $50 \%$ of patients with elevated TSH levels can exhibit normalized TSH in their second determination. The mean (SD) time between repeated TSH measurements was 18.93 \pm 13.11 months. The rate of progression from $\mathrm{SH}$ to $\mathrm{OH}$ during 5-year follow-up in patients in primary care was only $2.9 \%(122)(\mathrm{A})$.

Thyroid autoimmunity and TSH levels seem to influence the natural history of SH. In a 20 year follow-up of the Whickham survey, the annual progression rate of $\mathrm{SH}$ to overt hypothyroidism was $2.6 \%$ with elevated serum TSH levels $(>6 \mathrm{mU} / \mathrm{L})$ and $4.3 \%$ with both elevated TSH and positive antithyroid antibodies (107) (B). In a 13 year longitudinal analysis by the Busselton Health Study, female gender, and TSH cutoff of $2.5 \mathrm{mU} / \mathrm{L}$, combined with positive thyroid antibodies were the strongest predictors for long-term risk of hypothyroidism. In women with positive thyroid antibodies (TPOAbs or TgAbs), the prevalence of hypothyroidism at follow-up was $12.0 \%$ (95\% CI 3.0-21.0\%) when baseline TSH was $2.5 \mathrm{mU} /$ liter or less, $55.2 \%$ (95\% CI 37.1-73.3\%) for TSH between 2.5 and 4.0 $\mathrm{mU} /$ liter, and $85.7 \%$ (95\% CI 74.1-97.3\%) for TSH above $4.0 \mathrm{mU} /$ liter. (123) (A) (Table 4).

In smaller prospective studies, the progression to overt hypothyroidism was also related to initial TSH levels and to thyroid autoimmunity. In a prospective study of SH patients who were followed over a mean period of 9.2 years, the annual incidence of overt hypothyroidism varied according to TSH stratification, from $3.3 \%$ with TSH $6-12 \mathrm{mU} / \mathrm{L}$ to $11.4 \%$ with $\mathrm{TSH}>12$ $\mathrm{mU} / \mathrm{L}$. The cumulative incidence of overt hypothyroidism increased with higher TSH levels $(0 \%$ with TSH 4.0-6.0 mU/L, and 55.3\% with TSH > $6 \mathrm{mU} / \mathrm{L})$, and with positive microsomal antibodies $(58.5 \%$ vs. $23.2 \%$; $\mathrm{p}$ $=0.03)(32)(\mathbf{A})$. Similarly, in another prospective study with patients followed for a mean period of 31.7 months, TSH concentration was the only significant predictor for progression to overt hypothyroidism (124) (A). The incidence rate of overt hypothyroidism was $9.91 \%$ in the whole sample, and of $1.76 \%, 19.7 \%$ and $73.5 \%$ for patients with TSH levels of 5.0-9.9 mU/L, 10.0-14.9 $\mathrm{mU} / \mathrm{L}$, and 15.0-19.9 $\mathrm{mU} / \mathrm{L}$, respectively.

In Latin America, a study including women $<60$ years of age with mild elevation of serum TSH $(5-10 \mathrm{mU} / \mathrm{L})$, showed that most patients did not progress to overt hypothyroidism in a 3-year follow-up period, however, the presence of TPOAb and hypoechographic ultrasound pattern increased the risk of progression to overt disease (121) (A). The role of thyroid US on the progression of SH was also investigated in a previous and larger study, in which none of the patients with autoimmune thyroiditis and normal thyroid echogenicity became hypothyroid over an 18-month follow-up period (120) (A).

In two studies of an elderly population performed in the United Kingdom (125) (A) and in the USA (126), (B), the persistence in $\mathrm{SH}(77 \%$ and $56 \%$, respectively) was associated with higher TSH and with positive thyroid antibodies. In the American study, TSH levels $\geq$ $10 \mathrm{mU} / \mathrm{L}$ were independently associated with progression to overt hypothyroidism.

\section{Recommendation 8}

The progression to $\mathrm{OH}$ in patients with $\mathrm{SH}$ depends on the presence of thyroid antibodies and TSH baseline levels. Measurement of TPOAb and thyroid US in patients with $S H$ is useful to help predict a higher risk of progression to overt hypothyroidism. Grade A.

\section{ARE CLINICAL SYMPTOMS, DEPRESSION, AND COGNITIVE DYSFUNCTION ASSOCIATED WITH SUBCLINICAL HYPOTHYROIDISM?}

The effects of overt hypothyroidism and its treatment on the quality of life and cognitive function are well 
known, but it remains as an unresolved issue in regard to $\mathrm{SH}$.

Some population-based studies have investigated the effect of SH on quality of life, signs and symptoms, and cognitive function. In the Colorado Study (34), (B) overt and SH subjects all reported significantly more total symptoms than euthyroid individuals $(\mathrm{P}<$ $0.001)$. However, data from a cross-sectional study in Australia indicate that subclinical thyroid disease in women (18-75 years) of one community was not associated with decreased well-being or impaired health -related quality of life (127) (A). Furthermore, other large cross-sectional studies have also failed to find any significant effects on cognition, depression and anxiety in $\mathrm{SH}(38,99,128,129)(\mathbf{D}, \mathbf{A}, \mathbf{A}, \mathbf{B})$. To add more controversy to this topic, two studies from Brazil exploring neuropsychological function by different techniques arrived at opposite conclusions $(130,131)$ $(\mathbf{B}, \mathbf{B})$.

Some randomized controlled trials with limited sample sizes showed controversial results about the benefits of levothyroxine therapy on symptoms, quality of life, cognition and depression. In an RCT crossover study in 100 patients with $\mathrm{SH}$, levothyroxine correlated to a significant improvement in symptoms of tiredness (132) (A). On the other hand, in an RCT using highly sensitive tests, no effect of levothyroxine therapy was found on cognitive and emotionality, or in the disappearance of hypothyroid symptoms (133) (A). Similarly no evidence for treating elderly subjects with $\mathrm{SH}$ to improve cognition function was observed in an RCT applying sensitive tests (134) (A).

\section{Recommendation 9}

There are controversial results in the published literature regarding the effects of $S H$ on symptoms, quality of life, cognition and depression, but the panel concludes that there are hardly any symptoms or global neuropsychological dysfunction associated with $S H(D)$.

\section{IS THERE AN ASSOCIATION BETWEEN DYSLIPIDEMIA AND SUBCLINICAL HYPOTHYROIDISM?}

Thyroid hormone has multiple effects on the lipid synthesis and metabolism, and overt hypothyroidism is consistently associated to lipid abnormalities which are reversible with levothyroxine therapy $(135,136)$
$(\mathbf{D}, \mathbf{D})$, but this relationship is controversial in patients with SH (4) (D).

Results derived from observational studies are conflicting. In the Colorado Study, the mean total cholesterol and low-density lipoprotein cholesterol levels were significantly higher in $\mathrm{SH}$ than in euthyroid subjects, and lipid levels increased in a graded fashion as thyroid function declined (34) (A), but in this study, serum total cholesterol concentrations were not adjusted for age or sex.

In the Health, Aging and Body Composition Study, among 2,799 white and black participants aged 70 to 79 , a high TSH level $(>5.5 \mathrm{mU} / \mathrm{L})$ was associated with a $9 \mathrm{mg} / \mathrm{dL}$ higher total cholesterol, but the only subgroup that had significantly elevated cholesterol level associated with $\mathrm{SH}$, compared with the euthyroid state, was the one represented by black women (137) (B). In the Busselton Study (138) (A), serum total cholesterol was significantly higher in subjects with $\mathrm{SH}$ compared with euthyroid subjects. The difference was of borderline statistical significance after adjustment for age, and sex but remained significant for serum LDL-C even in those with mildly elevated TSH level $(\leq 10 \mathrm{mU} / \mathrm{L})$.

Data emerging from the NHANES III study showed no lipids abnormalities when adjusted for confounding variables (139) (B) and similar results were obtained from the Japanese-Brazilian Thyroid Study in Latin America (140) (A).

Multiple interventional studies have evaluated the effects of levothyroxine on lipid profiles in patients with $\mathrm{SH}$, with mixed results $(135,136)(\mathrm{D}, \mathrm{D})$. A meta-analysis of 13 studies (141) (B) found a significant decrease of serum total cholesterol levels following levothyroxine therapy, mainly in patients with elevated cholesterol values, but most of the selected studies had a non-randomized design. In contrast, a recent Cochrane systematic review (142) (A) of 12 randomized controlled trials comparing levothyroxine therapy with placebo or no treatment in adults with $\mathrm{SH}$ found only marginal evidence indicating that levothyroxine replacement improved total cholesterol levels, but no favorable effects were found on the other parameters of the lipid profile, such as HDL-C, LDL-C, triglycerides, ApoA, ApoB, or Lp(a). Most recently, several small randomized controlled trials found favorable effects of levothyroxine replacement therapy on the lipid profile (132,143-145) (B,B,B,B). 


\section{Recommendation 10}

The panel does not recommend routine levothyroxine treatment for patients with subclinical hypothyroidism aiming reduction on lipid atherogenic parameters, because the evidence on the association between subclinical bypothyroidism and lipid abnormalities is insufficient, data emerging from population studies are inconsistent and/or conflicting, and there is no consistent evidence showing favorable effects of levothyroxine replacement therapy alone on lipid profile of subclinical hypothyroidism patients. Grade D.

\section{IS THERE AN ASSOCIATION BETWEEN HIGH BLOOD PRESSURE AND SUBCLINICAL HYPOTHYROIDISM?}

In a meta-analysis $(146,147)(\mathbf{A})$ of all cross-sectional studies to investigate an association between $\mathrm{SH}$ and blood pressure alterations, there was significant difference in both systolic blood pressure and diastolic blood pressure in $\mathrm{SH}$ compared to control groups, with a weighted mean difference of $1.89 \mathrm{mmHg}$ and 0.75 $\mathrm{mmHg}$ for systolic and diastolic blood pressure, respectively. However, there is no randomized controlled trial investigating whether the treatment could modify blood pressure.

\section{IS THERE AN ASSOCIATION BETWEEN HEART FAILURE AND SUBCLINICAL HYPOTHYROIDISM?}

$\mathrm{SH}$ has been consistently associated with mild diastolic dysfunction at rest and on effort, but the studies are limited by their small size, design and selection bias (148-154) (B,B,B,B,C,C,C,). In a moderate-sized community-based sample, no association was observed between higher serum TSH concentrations and echocardiographic measurements (155) (A). Results regarding the effects on systolic function are conflicting (150154,156) (B,B,C,C,C,C). Data emerging from small and non-randomized clinical trials have shown reversal of myocardial dysfunction after levothyroxine replacement therapy in patients with SH $(148,149,151,156)$ $(\mathbf{B}, \mathbf{B}, \mathbf{B}, \mathbf{C})$. In two randomized controlled trials, impairment of myocardial function $(150,157)(\mathbf{B}, \mathbf{B})$ and structure (150) (B) were both reversed by levothyroxine substitution. The association of $\mathrm{SH}$ and heart failure has been demonstrated in elderly patients, but no study has yet assessed this association in younger age groups (103) (A). In the Health, Aging, and Body Composi- tion Study (158) (A) SH was related to a higher rate of incident and recurrent congestive cardiac failure with TSH levels of $7.0 \mathrm{mU} / \mathrm{L}$ or greater, compared with euthyroid participants, even after adjustment for cardiovascular risk factors.

Similarly, in the Cardiovascular Health Study (159) (A), subjects with TSH level $\geq 10 \mathrm{mU} / \mathrm{L}$ had a moderately elevated risk of heart failure over a mean 12 year follow-up compared to euthyroid subjects. In this study, the risk of congestive heart failure was not increased among older adults with TSH $<10 \mathrm{mU} / \mathrm{L}$. More recently, in The Prospective Study of Pravastatin in the Elderly at Risk (PROSPER), SH was significantly associated with a higher rate of heart failure (age- and sex- adjusted) at TSH threshold $>10 \mathrm{mU} / \mathrm{L}(160)($ A) in elderly with known high cardiovascular risk.

\section{Recommendation 11}

Data concerning the effects of subclinical hypothyroidism on the cardiac function and structure are conflicting. There are consistent evidence regarding the association of subclinical hypothyroidism with congestive heart failure in elderly patients, particularly for TSH level $>10 \mathrm{mU} / \mathrm{L}$ Grade A, but not for younger patients. There is no evidence concerning the role of levothyroxine treatment in reducing the incidence or progression of congestive heart failure on SH patients

\section{IS SUBCLINICAL HYPOTHYROIDISM ASSOCIATED TO CARDIOVASCULAR RISK?}

In the last few years, an increased number of prospective population-based cohort studies (100,138,140,158, 161-167) (A,A,A,A,A,A,A,A,A,B,B), have reported conflicting results on the potential relationship between $\mathrm{SH}$ and cardiovascular disease and mortality. These discrepancies may be due to differences in the populations studied in terms of age, sex, race/ethnicity, life style, TSH cutoffs, differences in confounders adjustments, follow-up period, and selection bias (1) (D).

Recent meta-analyses have also explored the potential associations between $\mathrm{SH}$ with coronary heart disease (CHD) and mortality. In two study-level meta-analyses $(168,169)(B)$, SH correlated significantly with an increased risk of $\mathrm{CHD}$, but in other three meta-analyses (170-172) (A,B,B), risks for CHD and mortality were only modestly increased. In one of these studies (171) (B), significance was obtained only for participants younger than 65 years of age. In another 
study-level meta-analysis, the risk of all-cause mortality was increased only in patients with $\mathrm{SH}$ and a comorbid condition (173) (A).

In the Japanese-Brazilian population, $\mathrm{SH}$ is an independent risk factor for all-cause mortality $(\mathrm{HR}=2.3$; 95\% CI 1.2-4.4), but not for cardiovascular mortality $(\mathrm{HR}=1.6 ; 95 \%$ CI 0.6-4.2) (140) (A).

These conflicting results emerging from these meta-analyses have been also attributed to heterogeneity among individual studies that used different TSH cutoffs, different confounding factors for adjustment, and different CHD definitions (174) (A). However, in a highly robust meta-analysis of 55,287 individual participants from 11 prospective cohort studies, $\mathrm{SH}$ correlated significantly to an increased risk of CHD events and CHD mortality in those with higher TSH levels compared with euthyroid participants. In this meta-analysis, CHD events were significantly increased in participants with TSH levels $\geq 10 \mathrm{mU} / \mathrm{L}$ ( $\mathrm{HR}=1.8995 \%$ CI 1.28 2.80 ), whereas $\mathrm{CHD}$ higher mortality rates were observed in those patients with TSH levels $\geq 7 \mathrm{mU} / \mathrm{L}$ (HR = 1.58; 95\% CI 1.10-2.27). There was a significant trend of increased risk at higher serum TSH concentrations for both CHD events and CHD mortality (174) (A).

Recently in a population based prospective study, treatment with levothyroxine of $\mathrm{SH}$ patients in the range of TSH between 5 and $10 \mathrm{mU} / \mathrm{L}$, has been shown to reduce fatal and non-fatal cardiovascular events. The beneficial effects of LT4 treatment to reduce cardiovascular risk were observed in patients below age 65 while in older patients there were no differences between treated and non-treated patients (175) (A).

\section{Recommendation 12}

There is available evidence suggesting an association between subclinical hypothyroidism and CHD events and mortality, particularly for subjects younger than 65. Grade A.

TSH concentrations $\geq 10 \mathrm{mU} / L$ were consistently associated with increased risk of CHD events and CHD mortality, whereas TSH level $\geq 7 \mathrm{mU} / L$ was related to CHD mortality. Grade A.

\section{WHICH PATIENTS WITH SUBCLINICAL HYPOTHYROIDISM SHOULD BE CONSIDERED FOR TREATMENT WITH THYROID HORMONES?}

Overall, in order to answer which patients with $\mathrm{SH}$ should be considered for treatment, we have to admit that whether levothyroxine replacement therapy will benefit an affected patient with $\mathrm{SH}$ still remains controversial, due to the lack of sufficient powered randomized placebo-controlled trials. As long as there is no robust evidence to guide clinicians as to when to treat a patient, the decision will continue to be based on the best clinical judgment and available evidence.

\section{Recommendation 13}

The panel recommends to treat all patients with TSH level persistently $>10 \mathrm{mU} / \mathrm{L}$, because at this TSH level, patients have an increased likelibood of progression to overt disease Grade A, and a higher rish of congestive heart failure, cardiovascular disease and mortality. Grade A.

For patients with mildly increased serum TSH levels (4.5-10 mU/L), treatment should be considered for those patients younger than 65 with increased cardiovascular risk (e.g., previous cardiovascular disease, diabetes, dyslipidemia, bypertension, metabolic syndrome), particularly when TSH level is persistently $>7 \mathrm{mU} / \mathrm{L}$. Grade A.

Levothyroxine therapy could be considered also for symptomatic middle-aged patients for a short period of time. If a clear beneficial effect is observed, levothyroxine therapy could be maintained. Grade D.

Treatment could yet be considered for patients with persistently mildly increased TSH levels with positive TPOAb and thyroid sonographic findings typical of autoimmune thyroiditis. Grade B.

\section{SHOULD ELDERLY PATIENTS BE CONSIDERED FOR TREATMENT?}

There is good evidence suggesting that $\mathrm{SH}$ is not related to symptoms or with disorders of cognition and mood in older persons $(99,128,129)(\mathbf{A}, \mathbf{B}, \mathbf{B})$, and there is strong evidence $(133,134)(\mathbf{A}, \mathbf{A})$ against treating elderly patients with $\mathrm{SH}$ aiming to improve cognitive function, quality of life and symptoms.

$\mathrm{SH}$ has been consistently related to a higher risk of incident and recurrent congestive heart failure in elderly subjects, particularly at TSH level $\geq 10 \mathrm{mU} / \mathrm{L}$ (158160) (A). However, it has been proposed that moderately increased serum TSH levels $(4.5-10 \mathrm{mU} / \mathrm{L})$ may represent a protective factor against cardiovascular risk and be associated with prolonged life span $(100,171,176,177)(\mathbf{A}, \mathbf{A}, \mathbf{B}, \mathbf{B})$.

On the other hand, in an individual participant data analysis, CHD outcomes in adults with $\mathrm{SH}$ did not differ significantly across age groups. For the specific age 
group of 80 years or older, there was neither a significant increased nor decreased risk of total mortality and CHD endpoints (174) (A). Physicians should acknowledge that TSH distribution curves for thyroid diseasefree subjects appear to shift progressively to higher TSH concentrations with age, suggesting that the increase in median TSH with age mainly reflects population shifts in TSH distribution rather than a thyroid dysfunction $(28,178)($ B,D $)$.

Physicians also have to consider harmful consequences of overtreatment with levothyroxine in elderly patients, in terms of the elevated risks of atrial fibrillation associated with subclinical hyperthyroidism in this age group $(24,165)(D, A)$.

\section{Recommendation 14}

The panel recommends against routine treatment for elderly (> 65 yr) and very-elderly (> 80 yr) patients with subclinical hypothyroidism at TSH levels< $10 \mathrm{mU} / \mathrm{L}$. Grade A.

The panel also recommends against treatment of $S H$ if the aim is to improve cognitive function in elderly people Grade A. However in $>65$ years old, treatment can be considered on an individual basis. Grade D.

\section{HOW SHOULD PATIENTS WITH HYPOTHYROIDISM BE TREATED AND MONITORED?}

Once the diagnosis of hypothyroidism is confirmed and decision for replacement therapy is made, the main treatment objective is to restore euthyroidism, improving symptoms and metabolic abnormalities associated with thyroid hormone deficiency. These goals are usually achieved restoring TSH and FT4 levels to normal. In the case of $\mathrm{SH}$, one study has shown that there are benefits (clinical improvement) in 1 out of 3 patients treated $(\mathrm{ARR}=32.4 ; 95 \% \mathrm{CI} 19-62.9$ with $\mathrm{NNT}=3$ (95\% CI 2-52) (179) (A).

The available drugs for this purpose are sodium levothyroxine (L-T4) and triiodothyronine (T3).

L-T4 has rapid and broad small intestinal absorption (jejunum and upper ileum), with peak concentrations 2-4 hours after ingestion. It has a longer half-life (7 days) and achieves more stable serum levels compared with T3, enabling a single daily dose use $(180)(\mathbf{C})$.

Its peripheral effect depends on a normal deionization process to generate physiological amounts of T3 at tissue level. This mechanism is regulated by type 2 deiodinase (DIO2) and is usually preserved in hypothyroid patients (181) (D).
Considering DIO2 function, and animal evidence of incomplete correction of T3 levels in peripheral tissues during L-T4 therapy (182) (D), some studies showed favorable effects in specific CNS functions using combined therapy with L-T4 and T3 (183) (B). Some genetic factors are suggested to be involved in these findings (184) (C). By contrast, recent meta-analysis consistently showed no significant clinical advantages of combined therapy compared with L-T4 alone, in terms of bodily pain, psychological symptoms, lipid profile, body weight, well-being, cognitive function or quality of life $(185,186)(\mathbf{A}, \mathbf{A})$.

\section{Recommendation 15}

We recommend levothyroxine as the drug of choice to treat bypothyroidism. Grade A.

We do not recommend routine use of combined therapy with levothyroxine and triiodothyronine for hypothyroid patients. Grade A.

\section{HOW SHOULD LEVOTHYROXINE BE USED?}

Levothyroxine intestinal absorption increases with low gastric $\mathrm{pH}$ and in a fasting state, and can be decreased in fed state. This finding favors ingestion of L-T4 during morning fast, delaying food ingestion for 30 minutes (187) (A). Conversely, recent small European and Indian studies demonstrated similar levels of thyroid hormones and no difference in clinical parameters using evening administration $(188,189)(\mathbf{B}, \mathbf{B})$, however, alimentary habits in Latin America could make these findings less applicable in our population.

Initial recommended daily dose for clinical hypothyroidism in < 60 years old patients is 1.6-1.8 $\mu \mathrm{g} /$ $\mathrm{kg}$ ideal body weight (190) (B). No differences were found between slow or full starting dose (191) (A).

Other inter-individual variables (etiology and severity of initial hypothyroidism), should be also considered to decide initial dose. In subclinical hypothyroidism, a lower dose (1.1-1.2 $\mu \mathrm{g} / \mathrm{kg}$ ) has been suggested (3). (D).

The goal of therapy is to normalize TSH levels. Recent recommendations suggest considering age-dependent target TSH levels in patients on L-T4 therapy. Thereby, younger patient $(<60$ years) should achieve TSH levels of 1-2.5 mU/L; in patients between 60-70 years TSH target should be 3-4 mU/L and 4-6 mU/L in patients older than 70 years (192) (D). 


\section{Recommendation 16}

The panel recommends that levothyroxine should be administered at least after 2 hours fast, 30 minutes before food intake Grade $A$. As an alternative, it could be administered in the evening. Grade B.

In clinical bypothyroidism, an initial levothyroxine daily dose of $1.6-1.8 \mathrm{\mu g} / \mathrm{kg}$ ideal body weight is recommended. Grade B.

In subclinical disease, we suggest an initial daily dose of $1.1-1.2 \mu \mathrm{g} / \mathrm{kg}$. Grade D.

Individual adjustment of levothyroxine therapy should be considered. Grade D.

\section{HOW TO INITIATE AND ADJUST DOSES IN ELDERLY AND IN PATIENTS WITH CARDIOPATHY?}

Levothyroxine therapy can induce relevant improvement in cardiovascular parameters in clinical and subclinical hypothyroidism (e.g. increase of cardiac output and decrease of systemic vascular resistance and end-diastolic volume). These effects are more evident in clinical than in subclinical disease $(149,193,194)$ (B,D,A). L-T4 therapy can also increase oxygen consumption, and induce myocardial ischemia in patients with underlying coronary artery disease.

Moreover, recent evidence suggests an increased fracture risk at usual doses in older L-T4 users $(>70$ years) $(195)(\mathbf{B})$.

\section{Recommendation 17}

In elderly patients (> 60 years) and also in those with ischemic cardiac disease or heart failure, we suggest starting levothyroxine therapy at lower doses (12.5-25 $\mu \mathrm{g} /$ day) Grade $D$, especially in subclinical hypothyroid patients. Grade B.

\section{DO BIOEQUIVALENCE DIFFERENCES EXIST BETWEEN LEVOTHYROXINE BRANDS?}

Levothyroxine has a narrow therapeutic index, and there is increased risk of inducing under- or overtreatment with slight dose variations. Bioequivalence studies have described relevant differences between some L-T4 generic and brand-name preparations (196) (C). Pharmacovigilance surveys also found frequent adverse events associated with unnoticed changes of L-T4 products (197) (D).

\section{Recommendation 18}

To prevent bioequivalence variations between different brands, the panel suggests avoiding changes in levothyro- xine preparations throughout treatment. In case of change, TSH and FT4 levels must be checked after 2 months. Grade D.

\section{HOW SHOULD LEVOTHYROXINE THERAPY BE MONITORED?}

Considering L-T4 half-life and distribution, and pituitary feedback, L-T4 therapy should be monitored measuring TSH and FT4 levels, 6 to 8 weeks after each dose modification, to avoid sustained under- or overtreatment (22) (D).

After euthyroidism is achieved, follow-up interval can be increased to 6 months and then annually.

Lifelong monitoring is required to check compliance and dosage and to take account of variations in dosage requirements.

In some clinical situations, more frequent monitoring is mandatory: (pregnancy (198) (B), significant changes in body weight (199) (B), concomitant medication and intercurrent diseases (200) (D).

\section{Recommendation 19}

The panel recommends TSH monitoring 6-8 weeks after any levothyroxine dose change, and yearly lifelong monitoring once euthyroidism is achieved. FT4 can be measured in early stages of treatment. Grade D.

\section{HOW TO APPROACH HYPOTHYROID PATIENTS WITH PERSISTENTLY HIGH LEVELS OF TSH DESPITE HIGH LEVOTHYROXINE DOSE?}

It should be taken into consideration that in follow-up studies, about $30 \%$ of patients on L-T4 therapy had abnormal TSH levels $(201,202)(\mathbf{A}, \mathbf{B})$.

Some foods (espresso coffee, soybean protein, dietary fiber), and drugs (ferrous and calcium salts, bile acid sequestering agents, sucralfate, aluminium hydroxide, proton pump inhibitors) can decrease L-T4 intestinal absorption $(200,203)(\mathbf{D}, \mathbf{B})$. In these cases, simultaneous ingestion with L-T4 should be avoided.

Chronic gastritis, Helicobacter pylori and Giardia infections can also decrease L-T4 absorption, and should be considered $(204,205)($ B,C).

Other drugs can accelerate L-T4 metabolism (phenytoin, carbamazepine, rifampin, tyrosine kinase inhibitors) requiring increase of intended dose (206) (B). 
If high L-T4 dose ( $>2 \mu \mathrm{g} / \mathrm{kg} /$ day) does not achieve TSH normalization, poor compliance, drug interference and malabsorption syndromes should be considered (22) (D).

\section{Recommendation 20}

After poor compliance and incorrect ingestion have been ruled out, the panel recommends considering possible food and drug interactions Grade B and also malabsorption syndromes that can alter levothyroxine absorption and metabolism. Grade D.

\section{HOW TO APPROACH PATIENTS WITH PERSISTENT HYPOTHYROID SYMPTOMS?}

In case of persistent hypothyroidism symptoms despite adequate treatment, other diseases such as anemia or depression should be excluded. In case of adrenal adrenal insufficiency $(207,208)($ C,C), a pseudo hypothyroidism may be present that resolves with glucorticoid therapy that normalizes high TSH levels.

Fatigue-related symptoms have been described more frequently in patients with autoimmune hypothyroidism when compared to other causes of hypothyroidism. This effect has been related to the autoimmune process, independently of TSH levels $(209,210)$ (B).

Some strategies to improve hypothyroidism-related symptoms have been described (an increase in levothyroxine dose to achieve low-normal TSH levels, combination therapy with triiodotironine) but there is no solid evidence to support these practices $(211,212)(\mathbf{B})$.

\section{Recommendation 21}

If hypothyroid symptoms persist despite adequate treatment, other comorbidities should be discarded Grade C. Increased levothyroxine dose or combination therapy with triiodotironine are not recommended. Grade $B$.

\section{HOW TO TREAT MYXEDEMA COMA?}

Myxedema coma is the most severe and life threatening form of hypothyroidism, with high lethality (25-60\%). Usual precipitating factors are discontinuation of therapy, infections and exposure to cold. Myxedema coma can ensue from long standing untreated hypothyroi$\operatorname{dism}(213,214)(\mathbf{D}, \mathbf{D})$.

Its clinical manifestations include hypothermia, respiratory depression, cardiovascular instability and altered mental status.
Due to the low prevalence of myxedema coma, very few randomized controlled trials have been undertaken to specify outcome predictors and treatment alternatives.

There are many prognostic factors described in small population studies, including: critical care scores (SOFA, APACHE, GCS), respiratory failure and consciousness: these factors can stratify patients with higher mortality rates (215) (B).

Principles of therapy are rapid thyroid hormone replacement, treatment of precipitating factors and provision of advanced life support in intensive care units.

Thyroid hormone replacement is the backbone of therapy. It can be based in L-T4 administration at high doses: (300-500 $\mu \mathrm{g} /$ day IV followed by maintenance dose $50-100 \mu \mathrm{g} /$ day; or $500-1000 \mu \mathrm{g} /$ day oral followed by 100-200 $\mu \mathrm{g} /$ day). Triiodothyronine can be added to therapy at 10-20 $\mu \mathrm{g}$ bolus followed by $10 \mu \mathrm{g}$ every 4-6 hours. This initial plan can be followed by L-T4 maintenance therapy once the patient is stable $(216,217)(\mathbf{B}, \mathbf{B})$.

Primary or secondary adrenal insufficiency can be associated with severe hypothyroidism and myxedema coma. Empirical glucocorticoid therapy (intravenous hydrocortisone $50-100 \mathrm{mg}$ every $8 \mathrm{~h}$ ) should be considered in these patients (218) (D).

Precipitating factors management includes progressive hypothermia correction, broad-spectrum antibiotic therapy, and management of concomitant disease (myocardial infarction, cerebrovascular accident, drug-related respiratory depression or trauma).

Advanced life support involves a multidisciplinary approach and should include cautious volume expansion, ventilatory support and routine steroid replacement therapy.

\section{Recommendation 22}

Myxedema coma is the most severe form of hypothyroidism. We recommend a multidisciplinary approach based on advanced life support, correction of precipitating factors and comorbidities, and high initial levothyroxine dose. Grade D.

\section{HOW ARE HYPOTHYROIDISM AND SUBCLINICAL HYPOTHYROIDISM DEFINED IN PREGNANT WOMEN?}

TSH levels are acknowledged to be the most sensitive method for the diagnosis of hypothyroidism in any population. However, the definition of the reference 
values is still a subject of great discussion. More recently, it has been proposed that the reference value range should be individualized for specific populations (219) (B), including pregnant women and even with different ranges for each trimester.

Studies done with pregnant women show that the TSH blood levels are lower than the general population, with a reduction of the lower and upper limits. The TSH upper limit reference values of $2.5 \mathrm{mU} / \mathrm{L}$ for the first trimester, and of 2.5-3.0 for the second and third trimesters shown in recently published guidelines (220) (D) are based on observational population studies that assess TSH levels in pregnant women without positive anti-thyroid antibodies(221-223) (B,B,B).

Besides TSH, free T4 levels can help diagnose $\mathrm{SH}$ or OH. Such levels ideally should be measured by mass spectrometry or gas chromatography (224) (B). However, these methods are too complex and expensive for routine use and, for this reason, most laboratories use IA that estimate FT4.

The methods for measuring free T4 are flawed for the follow-up of pregnant women because of the low levels of albumin. To overcome this situation, some authors advocate the measurement of total T4 (adjusted by 1.5 factor to compensate for TBG changes) or as part of the free T4 index (225) (B).

\section{Recommendation 23}

As with non-pregnant women, the elevation of TSH blood levels is the parameter for diagnosing primary hypothyroidism in pregnant women, considering the superior limits for each trimester of pregnancy. Grade D.

Ideally the reference value range for each trimester should be known in specific populations. Grade B.

When the elevation of the TSH level is confirmed, free T4 should be measured Grade B, in order to classify the bypothyroidism as clinical or overt $(\mathrm{OH})$ and subclinical (SH). Grade D.

- TSH > 2.5-10.0 mUL with normal free T4: $S H$.

- TSH> 2.5-10.0 mUL with low levels of free T4: $\mathrm{OH}$.

- $T S H \geq 10.0 \mathrm{mUL}$, despite the level of free T4: $\mathrm{OH}$.

\section{WHEN AND HOW TO SCREEN HYPOTHYROIDISM IN PREGNANT WOMEN?}

\section{"Universal screening" vs. "case-finding"}

In order for a "screening" test to be appropriate, it should reduce mortality and/or morbidity, or at least delay and/or avoid an unfavorable outcome (related to it) by changing management or treatment. The proposed test should be convenient, have low cost and be of easy access. Finally, the test should not present a risk to the patient $(226,227)(\mathbf{D}, \mathbf{D})$ When determining the need for a "screening" test in a population, the following questions must be answered:

a) Is the disease prevalent in asymptomatic patients? American data show that the prevalence of elevated TSH in pregnant women is around $2.5 \%$, with approximately $0.3-0.5 \%$ of these, cases of $\mathrm{OH}(220,228)$ $(\mathbf{D}, \mathbf{B})$. Studies are clear in associating $\mathrm{OH}$ during pregnancy with adverse obstetric and neonatal risks, as well as intellectual risks to their children (220,229-231) $(\mathbf{D}, \mathbf{B}, \mathbf{B}, \mathbf{B})$. However, a recent study (232) (A) showed that the prenatal screening and maternal treatment for hypothyroidism did not result in improved cognitive function in children at 3 years of age.

b) Is the screening test simple and reliable? A "screening" test should be sensitive and low cost. It is known that TSH measurement is the most sensitive method for the diagnosis of primary hypothyroidism, as mentioned in "How to define clinical and subclinical hypothyroidism during pregnancy?".

Studies show that the positivity of TPOAb, despite the levels of TSH may be associated with unfavorable outcomes (233-235) (B,B,B), but no studies evaluating the effectiveness of screening through the measurement of ATPO have been conducted to date $(220,236,237)(\mathbf{D}, \mathbf{A}, \mathbf{B})$.

c) Will the identification through the screening generate any change in case management? As mentioned earlier, $\mathrm{OH}$ should be treated during pregnancy $(220,229-231)(\mathbf{D}, \mathbf{B}, \mathbf{B}, \mathbf{B})$. The association between $\mathrm{SH}$ and adverse obstetric outcomes have been demonstrated in several $(229,238,239)(\mathbf{B})$ but not all, studies (240) (A).

d) Is the screening cost-effective?

Some studies have assessed the cost-effectiveness of universal "screening" and concluded that, when considering SH during pregnancy, it is not yet established if $\mathrm{SH}$ is a cause of intellectual deficit in children (52,241-243) (A,B,B,B). Risk group for hypothyroidism comprises women $>30$ years of age, presence of other autoimmune diseases, previous cervical irradiation, use of drugs that interfere with thyroid function (amiodarone, lithium), use of iodinated contrast media, presence of circulating TPOAb, personal history of previous thyroidectomy or thyroid disease, family history 
of thyroid disease, goiter and signs and symptoms of hypothyroidism (220) (D).

One of the most recent studies (244) (B) about cost-effectiveness of universal screening and risk-based screening for autoimmune thyroid disease in pregnant women, using a decision-analytic model, compared the incremental cost per quality-adjusted-life-year between universal screening, high-risk screening and no screening. They concluded that universal screening is cost-effective, not only compared with no screening but also compared with screening of high-risk women.

\section{Recommendation 24}

We recommend evaluating thyroid function in the high risk pregnant population. Grade D.

\section{WHAT IS THE ROLE OF THYROID AUTOIMMUNITY IN FERTILITY AND PREGNANCY?}

AITD is the most common autoimmune disease and is the leading cause of hypothyroidism among women. The sum of small studies analyzing the prevalence of AITD in infertile women suggests a significant relative risk of 2.1 (245) (B). Also, a correlation has been described between circulating TPOAb and endometriosis, as well as polycystic ovary syndrome $(246,247)($ B,C).

In addition, an association with autoimmune oophoritis has also been reported $(246,247)(B, C)$. One question still unanswered is whether there is a causal link between the presence of circulating TPOAb and disorders that interfere with fertility, or if there is only a finding of an association. In 1990, an association between pregnancy loss and TPOAb, with increase in the risk of miscarriage $17 \%$ versus $8.4 \%$ with negative antibodies was reported (248) (B). A meta-analysis evaluating only cohort studies from women with recurrent miscarriage didn't confirm this association, with $\mathrm{OR}=$ $4.22(0.97-18.44)(234)(B)$ while another meta-analysis found an increased risk with an OR of 2.73 (95\% CI 2.20-3.40) in eight case-controlled and ten longitudinal (OR, 2.30; 95\% CI, 1.80-2.95) studies (249) (B).

In the studies of assisted reproduction, there is no agreement regarding an association between positive antithyroid antibodies with implantation failure (245) (B). However, some studies have shown an association with miscarriages in the first trimester (even in the absence of anti-cardiolipin antibodies) (250-254) (B,C,C,C,C).
It is assumed that autoimmunity can have an impact on pregnancy through two mechanisms. One is through the interference in the adaptive mechanisms of the high demand on the thyroid, and the other, through the association with an autoimmune environment with direct effects on the placenta and the fetus as a consequence of the generalized activation of the immune system $(220,255-257)$ (D,B,D).

The hypothesis is that the autoimmunity would prevent the adaptive thyroid reaction for the high demand would result in lower levels of thyroid hormones. Consequently, the mechanisms for the resulting harm to pregnancy are based on the direct effect of the hormones on the different aspects of the mother-fetus unit. Thyroid hormones seem to regulate angiogenic growth factors and cytokine production, as well as trophoblastic proliferation and placenta and decidua development $(258,259)(\mathbf{D}, \mathbf{D})$.

In a recent meta-analysis (234) (B), results of five cohort studies that assessed the impact of AITD (with preserved thyroid function) on the risk of premature labor were included with $\mathrm{OR}=2.07$ (95\% CI 1.17-3.68). All of the studies showed a positive association, and the cumulative analysis demonstrated an OR of 2.1 (95\% CI 1.2-3.7; $\mathrm{p}=0.01)$. In this same meta-analysis $(234)(\mathbf{B}), 31$ studies that assessed the impact of AITD (with compensated thyroid function) on the risk of miscarriage were also included. The studies differed in various aspects. Some had followed a cohort $(235-237,248,250,252,253,260-271)$ ( B,A,B,B,B,B,B,A,B-B) and others were "case-controlled" studies $(251,254,272-275)(\mathbf{C}, \mathbf{C}, \mathbf{C}, \mathbf{C}, \mathbf{C})$.

The studies also differed among themselves in that they included patients with different characteristics: infertile patients, patients with recurrent miscarriages or pregnant women. Altogether, the pooled analysis demonstrated a positive association between the risk of abortion and AITD with normal thyroid function [OR $=3.9(2.4-6.1 \mathrm{p}<0.01)$ for the cohort and $\mathrm{OR}=1.80$ (95\% CI $1.25-2.60 ; \mathrm{p}=0.002)$ for the "case-control" studies]. Results are more homogeneous when the patients have a history of infertility. Interestingly, in this meta-analysis, advanced age was not a risk factor associated with autoimmunity, however, elevated TSH levels were accompanied by AITD.

\section{Recommendation 25}

With the evidence that there is a bigher demand on the thyroid during pregnancy and that women who have AITD have a higher risk of $\mathrm{SH}$ or $\mathrm{OH}$ in this situation, 
monitoring TSH levels is imperative in these pregnant women (every 4 weeks). Grade D.

\section{WHEN AND HOW TO TREAT HYPOTHYROIDISM IN PREGNANT WOMEN?}

As early as 4-6 weeks of gestation, there is an increased need of T4 which continues to rise, up to 16-20 weeks of pregnancy, when it becomes stable up to delivery.

As there have been several reports of materno-fetal complications in patients with positive TPOAb and $\mathrm{SH}$, even if there are no RCTs demonstrating the benefit of treatment, levothyroxine should be used to achieve TSH target for each trimester $(220,276)(\mathbf{D}, \mathbf{D})$. Moreover, levothyroxine therapy to treat pregnant euthyroid women with positive TPOAb has to be considered since it significantly reduced preterm birth by $72 \%$ (RR 0.28 ; 95\% CI 0.10 to 0.80 ) (277) (A).

With regards to women with hypothyroidism previous to pregnancy, it has been suggested to increase their levothyroxine dose by approximately 30 percent as soon as pregnancy is confirmed (278) (B). Most recently, in a prospective trial, a recommendation was made for a two-tablet-per week increase of the baseline levothyroxine dose (nine tablets per week instead of seven tablets) in order to reduce the risk of maternal hypothyroidism during the first trimester (198) (B). Furthermore, in women with primary hypothyroidism, TSH levels of $1.2 \mathrm{mU} / \mathrm{L}$ during preconception have shown to be related with TSH levels under $2.5 \mathrm{mU} / \mathrm{L}$, the desired goal during the $\mathrm{l}^{\text {st }}$ trimester of pregnancy (279) (B).

\section{Recommendation 26}

When planning to conceive, the dose of LT4 should be adjusted to maintain plasma TSH $<2.5 \mathrm{mU} / L$. Grade D.

Hypothyroid women who become pregnant and do not have immediate access to the physician must increase the dose of LT4 by 25\%-30\% or increase by two additional LT4 tablets per week. Grade B.

Pregnant women with $S H$ who have positive serum TPOAb should be treated with LT4. Grade A.

For pregnant women with negative serum TPOAb and $S H$, data are insufficient to recommend for or against universal treatment. Grade D.

If it has been decided not to treat SH at the beginning of pregnancy, patients should be monitored for the progression to $\mathrm{OH}$, with free T4 and TSH approximately every 4 weeks up to 16-20 weeks of gestation,

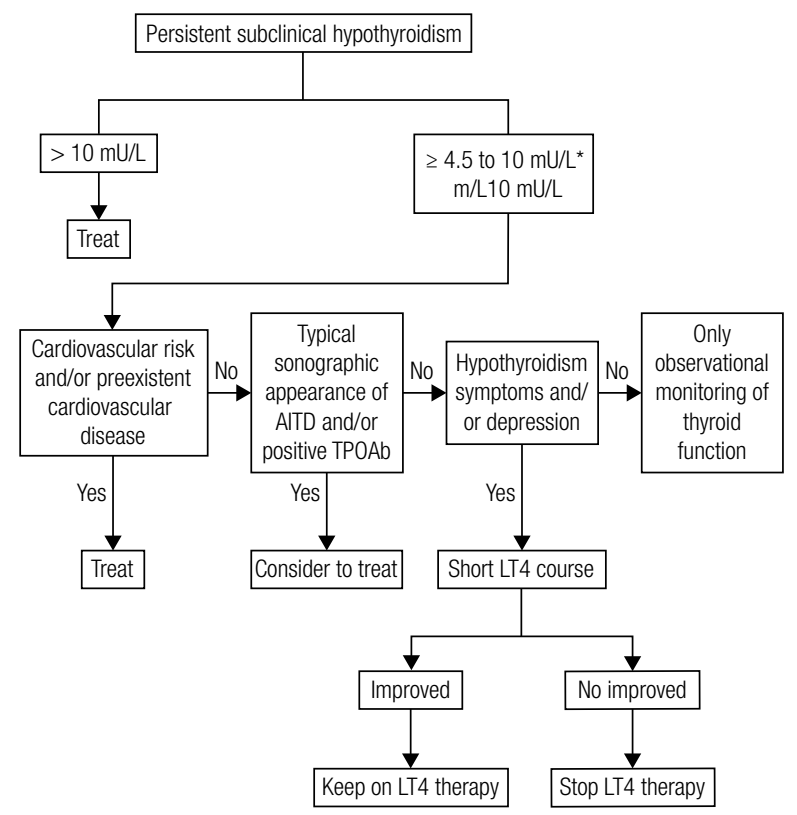

* In patients over 65 years of age, this algorithm should be applied on an individual basis.

Figure 1. Algorithm for the treatment of subclinical hypothyroidism in adult subjects (except for infertile and pregnant women).

and at least once between 26 and 32 weeks. Grade D $\mathrm{OH}$ women, even with TSH above $10 \mathrm{mU} / \mathrm{L}$, should be treated, whatever their FT4 level. Grade D.

The goal of treatment with LT4 is to normalize serum TSH within the reference range for each trimester of pregnancy. Grade D.

Disclosure: no potential conflict of interest relevant to this article was reported.

\section{REFERENCES}

1. Biondi B, Cooper DS. The clinical significance of subclinical thyroid dysfunction. Endocr Rev. 2008;29:76-131.

2. Wiersinga W. 2010 Adult hypothyroidism. In: Thyroid Disease Manager. Available at: www.thyroidmanager.org/chapter/adulthypothyroidism/\#toc-9-2-definition-and-epidemiology-of-hypothyroidism. Accessed: Nov 16, 2011.

3. Levalle O, Pusiol E, Silva Croome M. Disfunción tiroidea subclínica. Disfunción tiroidea y amiodarona. RAEM. 2009;46:19-24.

4. Cooper DS, Biondi B. Subclinical thyroid disease. Lancet. 2012;379:1142-54

5. Feld A, Busala AE. [Research and cure: knowledge and prophylaxis of endemic goiter in Argentina (1916-1958).]. Asclepio. 2010;62:375-404.

6. Li M, Eastman CJ.The changing epidemiology of iodine deficiency. Nat Rev Endocrinol. 2012;8:434-40

7. Pretell EA, Delange F, Hostalek U, Corigliano S, Barreda L, Higa AM, et al. lodine nutrition improves in Latin America. Thyroid. 2004;14:590-9. 
8. Camargo RY, Tomimori EK, Neves SC, I GSR, Galrao AL, Knobel $M$, et al. Thyroid and the environment: exposure to excessive nutritional iodine increases the prevalence of thyroid disorders in Sao Paulo, Brazil. Eur J Endocrinol. 2008;159:293-9.

9. Spencer CA, LoPresti JS, Patel A, Guttler RB, Eigen A, Shen D, et al. Applications of a new chemiluminometric thyrotropin assay to subnormal measurement. J Clin Endocrinol Metab. 1990;70:453-60.

10. Klee GG, Hay ID. Biochemical testing of thyroid function. Endocrinol Metab Clin North Am. 1997;26:763-75.

11. Glenn GC. Practice parameter on laboratory panel testing for screening and case finding in asymptomatic adults. Laboratory Testing Strategy Task Force of the College of American Pathologists. Arch Pathol Lab Med. 1996;120:929-43.

12. Indra R, Patil SS, Joshi R, Pai M, Kalantri SP. Accuracy of physical examination in the diagnosis of hypothyroidism: a cross-sectional, double-blind study. J Postgrad Med. 2004;50:7-11; discussion 11.

13. lacoviello M, Guida P, Guastamacchia E, Triggiani V, Forleo C, Catanzaro $R$, et al. Prognostic role of sub-clinical hypothyroidism in chronic heart failure outpatients. Curr Pharm Des. 2008;14:2686-92.

14. Goulis DG, Tsimpiris N, Delaroudis S, Maltas B, Tzoiti M, Dagilas A, et al. Stapedial reflex: a biological index found to be abnormal in clinical and subclinical hypothyroidism. Thyroid. 1998;8:583-7.

15. Roden M, Nowotny P, Hollenstein U, Schneider B, Vierhapper $H$, WaldhausI W. Equivalent discrimination among states of thyroid function by immunochemiluminimetric and immunoradiometric determination of thyrotropin. Clin Chem. 1993;39:544-7.

16. Canaris GJ, Steiner JF, Ridgway EC. Do traditional symptoms of hypothyroidism correlate with biochemical disease? J Gen Intern Med. 1997;12:544-50.

17. de los Santos ET, Starich GH, Mazzaferri EL. Sensitivity, specificity, and cost-effectiveness of the sensitive thyrotropin assay in the diagnosis of thyroid disease in ambulatory patients. Arch Intern Med. 1989;149:526-32.

18. Attia J, Margetts $P$, Guyatt G. Diagnosis of thyroid disease in hospitalized patients: a systematic review. Arch Intern Med. 1999;159:658-65.

19. Spencer C, Eigen A, Shen D, Duda M, Qualls S, Weiss S, et al. Specificity of sensitive assays of thyrotropin (TSH) used to screen for thyroid disease in hospitalized patients. Clin Chem. 1987;33:1391-6.

20. Stockigt J. Assessment of thyroid function: towards an integrated laboratory--clinical approach. Clin Biochem Rev. 2003;24:109-22.

21. Takats IK, Peter F, Rimanoczi E, Dohan O, Foldes J, Vadasz J, et al. The blood spot thyrotropin method is not adequate to screen for hypothyroidism in the elderly living in abundant-iodine intake areas: comparison to sensitive thyrotropin measurements. Thyroid. 2000;10:79-85.

22. Baloch Z, Carayon P, Conte-Devolx B, Demers LM, Feldt-Rasmussen $\mathrm{U}$, Henry JF, et al. Laboratory medicine practice guidelines. Laboratory support for the diagnosis and monitoring of thyroid disease. Thyroid. 2003;13:3-126.

23. van Deventer HE, Mendu DR, Remaley AT, Soldin SJ. Inverse loglinear relationship between thyroid-stimulating hormone and free thyroxine measured by direct analog immunoassay and tandem mass spectrometry. Clin Chem. 2011;57:122-7.

24. Surks MI, Ortiz E, Daniels GH, Sawin CT, Col NF, Cobin RH, et al. Subclinical thyroid disease: scientific review and guidelines for diagnosis and management. JAMA. 2004;291:228-38.

25. Hollowell JG, Staehling NW, Flanders WD, Hannon WH, Gunter EW, Spencer CA, et al. Serum TSH, T(4), and thyroid antibodies in the United States population (1988 to 1994): National Health and Nutrition Examination Survey (NHANES III). J Clin Endocrinol Metab. 2002;87:489-99.
26. Andersen S, Pedersen KM, Bruun NH, Laurberg P. Narrow individual variations in serum $\mathrm{T}(4)$ and $\mathrm{T}(3)$ in normal subjects: a clue to the understanding of subclinical thyroid disease. J Clin Endocrinol Metab. 2002;87:1068-72.

27. Baskin HJ, Cobin RH, Duick DS, Gharib H, Guttler RB, Kaplan MM, et al. American Association of Clinical Endocrinologists medical guidelines for clinical practice for the evaluation and treatment of hyperthyroidism and hypothyroidism. Endocr Pract. 2002;8:457-69.

28. Surks MI, Hollowell JG. Age-specific distribution of serum thyrotropin and antithyroid antibodies in the US population: implications for the prevalence of subclinical hypothyroidism. J Clin Endocrinol Metab. 2007;92:4575-82.

29. Boucai L, Hollowell JG, Surks MI. An approach for development of age-, gender-, and ethnicity-specific thyrotropin reference limits. Thyroid. 2011;21:5-11.

30. Diez JJ, Iglesias P, Burman KD. Spontaneous normalization of thyrotropin concentrations in patients with subclinical hypothyroidism. J Clin Endocrinol Metab. 2005;90:4124-7.

31. British Thyroid Association, Association for Clinical Biochemistry. 2006 UK Guidelines for the Use of Thyroid Function Tests. Association of Clinical Biochemistry, British Thyroid Association and British Thyroid Foundation. Available at: http://www.britishthyroid-association.org/info-forpatients/Docs/TFT_guideline_final_version_July_2006.pdf. Accessed: Oct 8, 2011.

32. Huber G, Staub JJ, Meier C, Mitrache C, Guglielmetti M, Huber P, et al. Prospective study of the spontaneous course of subclinical hypothyroidism: prognostic value of thyrotropin, thyroid reserve, and thyroid antibodies. J Clin Endocrinol Metab. 2002;87:3221-6.

33. Tunbridge WM, Evered DC, Hall R, Appleton D, Brewis M, Clark F, et al. The spectrum of thyroid disease in a community: the Whickham survey. Clin Endocrinol (Oxf). 1977;7:481-93.

34. Canaris GJ, Manowitz NR, Mayor G, Ridgway EC. The Colorado thyroid disease prevalence study. Arch Intern Med. 2000;160:526-34.

35. Sichieri R, Baima J, Marante T, de Vasconcellos MT, Moura AS, Vaisman M. Low prevalence of hypothyroidism among black and Mulatto people in a population-based study of Brazilian women. Clin Endocrinol (Oxf). 2007;66:803-7.

36. Tachman ML, Guthrie GP, Jr. Hypothyroidism: diversity of presentation. Endocr Rev. 1984;5:456-65.

37. Zulewski $H$, Muller B, Exer P, Miserez AR, Staub JJ. Estimation of tissue hypothyroidism by a new clinical score: evaluation of patients with various grades of hypothyroidism and controls. $J$ Clin Endocrinol Metab. 1997;82:771-6.

38. Billewicz WZ, Chapman RS, Crooks J, Day ME, Gossage J, Wayne $E$, et al. Statistical methods applied to the diagnosis of hypothyroidism. Q J Med. 1969;38:255-66.

39. Robuschi G, Safran M, Braverman LE, Gnudi A, Roti E. Hypothyroidism in the elderly. Endocr Rev. 1987;8:142-53.

40. Levy EG. Thyroid disease in the elderly. Med Clin North Am. 1991;75:151-67.

41. Finucane $P$, Anderson C. Thyroid disease in older patients. Diagnosis and treatment. Drugs Aging. 1995;6:268-77.

42. Bergoglio L. 2010 Perfiles hormonales y de sustancia relacionada. In Tratado Argentino de Tiroides. Available at: http://www. tratadodetiroides.com.ar/swf/cap20/Cap20.aspx. Accessed: Nov 26, 2012.

43. Hutfless $\mathrm{S}$, Matos $\mathrm{P}$, Talor MV, Caturegli P, Rose NR. Significance of prediagnostic thyroid antibodies in women with autoimmune thyroid disease. J Clin Endocrinol Metab. 2011;96:E1466-71.

44. Eddy D. How to think about screening. In: Eddy D (ed). Common Screening Tests. Philadelphia: American Coll Physicians. 1991, p. 1-21.

45. Rugge B, Balshem H, Sehgal R, Relevo R, Gorman P, Helfand M. Screening and Treatment of Subclinical Hypothyroidism or Hy- 
perthyroidism. Rockville (MD): Agency for Healthcare Research and Quality (US); 2011 Oct. Report No.: 11(12)-EHC033-EF. 2011.

46. Helfand M, Redfern CC. Clinical guideline, part 2. Screening for thyroid disease: an update. American College of Physicians. Ann Intern Med. 1998;129:144-58.

47. Gharib $H$, Cobin R, Dickey R. Subclinical hypothyroidism during pregnancy: position statement from the American Association of Clinical Endocrinologists. Endocr Pract. 1999;5:367-8.

48. Ladenson PW, Singer PA, Ain KB, Bagchi N, Bigos ST, Levy EG, et al. American Thyroid Association guidelines for detection of thyroid dysfunction. Arch Intern Med. 2000;160:1573-5.

49. Helfand M. Screening for subclinical thyroid dysfunction in nonpregnant adults: a summary of the evidence for the U.S. Preventive Services Task Force. Ann Intern Med. 2004;140:128-41.

50. Tektonidou MG, Anapliotou M, Vlachoyiannopoulos P, Moutsopoulos HM. Presence of systemic autoimmune disorders in patients with autoimmune thyroid diseases. Ann Rheum Dis. 2004;63:1159-61.

51. Nakamura H, Usa T, Motomura M, Ichikawa T, Nakao K, Kawasaki $E$, et al. Prevalence of interrelated autoantibodies in thyroid diseases and autoimmune disorders. J Endocrinol Invest. 2008;31:861-5.

52. Vaidya B, Anthony S, Bilous M, Shields B, Drury J, Hutchison S, et al. Detection of thyroid dysfunction in early pregnancy: universal screening or targeted high-risk case finding? J Clin Endocrinol Metab. 2007;92:203-7.

53. BrixTH, Kyvik KO, Christensen K, Hegedus L. Evidence for a major role of heredity in Graves' disease: a population-based study of two Danish twin cohorts. J Clin Endocrinol Metab. 2001;86:930-4.

54. StriederTG, Prummel MF,Tijssen JG, Endert E, Wiersinga WM. Risk factors for and prevalence of thyroid disorders in a cross-sectional study among healthy female relatives of patients with autoimmune thyroid disease. Clin Endocrinol (Oxf). 2003;59:396-401.

55. Dittmar M, Kahaly GJ. Polyglandular autoimmune syndromes: immunogenetics and long-term follow-up. J Clin Endocrinol Metab. 2003;88:2983-92.

56. Perros P, McCrimmon RJ, Shaw G, Frier BM. Frequency of thyroid dysfunction in diabetic patients: value of annual screening. Diabet Med. 1995;12:622-7.

57. Kordonouri O, Maguire AM, Knip M, Schober E, Lorini R, Holl RW, et al. Other complications and associated conditions with diabetes in children and adolescents. Pediatr Diabetes. 2009;10 Suppl 12:204-10.

58. Gerstein HC. Incidence of postpartum thyroid dysfunction in patients with type I diabetes mellitus. Ann Intern Med. 1993;118:41923.

59. Ramasamy V, Kadiyala R, Fayyaz F, Mallipedhi A, Baglioni $P$, Okosieme OE. Value of baseline serum thyrotropin as a predictor of hypothyroidism in patients with diabetes mellitus. Endocr Pract. 2011;17:26-32.

60. Bertram U, Halberg P. Organ antibodies in Sjogren's syndrome. Acta Allergol. 1965;20:472-83.

61. Hansen BU, Ericsson UB, Henricsson V, Larsson A, Manthorpe R, Warfvinge G. Autoimmune thyroiditis and primary Sjogren's syndrome: clinical and laboratory evidence of the coexistence of the two diseases. Clin Exp Rheumatol. 1991;9:137-41.

62. Zeher M, Horvath IF, Szanto A, Szodoray P. Autoimmune thyroid diseases in a large group of Hungarian patients with primary Sjogren's syndrome. Thyroid. 2009;19:39-45.

63. Karsh J, Pavlidis N, Weintraub BD, Moutsopoulos HM. Thyroid disease in Sjogren's syndrome. Arthritis Rheum. 1980;23:1326-9.

64. Perez B, Kraus A, Lopez G, Cifuentes M, Alarcon-Segovia D. Autoimmune thyroid disease in primary Sjogren's syndrome. Am J Med. 1995;99:480-4.
65. D'Arbonneau F, Ansart S, Le Berre R, Dueymes M, Youinou P, Pennec YL. Thyroid dysfunction in primary Sjogren's syndrome: a long-term followup study. Arthritis Rheum. 2003;49:804-9.

66. Punzi L, Ostuni PA, Betterle C, De Sandre P, Botsios C, Gambari PF. Thyroid gland disorders in primary Sjogren's syndrome. Rev Rhum Engl Ed. 1996;63:809-14.

67. Jara LJ, Navarro C, Brito-Zeron Mdel P, Garcia-Carrasco M, Escarcega RO, Ramos-Casals M. Thyroid disease in Sjogren's syndrome. Clin Rheumatol. 2007;26:1601-6.

68. Dessein PH, Joffe BI, Stanwix AE. Subclinical hypothyroidism is associated with insulin resistance in rheumatoid arthritis. Thyroid. 2004;14:443-6.

69. El-Sherif WT, El Gendi SS, Ashmawy MM, Ahmed HM, Salama MM. Thyroid disorders and autoantibodies in systemic lupus erythematosus and rheumatoid arthritis patients. Egypt $\mathrm{J}$ Immunol. 2004;11:81-90.

70. Chan AT, Al-Saffar Z, Bucknall RC. Thyroid disease in systemic lupus erythematosus and rheumatoid arthritis. Rheumatology (Oxford). 2001;40:353-4.

71. Daneshpazhooh M, Mostofizadeh GM, Behjati J, Akhyani M, Robati RM. Anti-thyroid peroxidase antibody and vitiligo: a controlled study. BMC Dermatol. 2006;6:3.

72. Hegedus L, Heidenheim M, Gervil M, Hjalgrim H, Hoier-Madsen $M$. High frequency of thyroid dysfunction in patients with vitiligo. Acta Derm Venereol. 1994;74:120-3.

73. Kumar KV, Priya S, Sharma R, Kapoor U, Saini M, Bisht YS. Autoimmune thyroid disease in patients with vitiligo: prevalence study in India. Endocr Pract. 2012;18:194-9.

74. Lobo Ede H, Khan M, Tew J. Community study of hypothyroidism in Down's syndrome. Br Med J. 1980;280:1253.

75. Prasher V, Ninan S, Haque S. Fifteen-year follow-up of thyroid status in adults with Down syndrome. J Intellect Disabil Res. 2011;55:392-6.

76. Chen MH, Chen SJ, Su LY,Yang W. Thyroid dysfunction in patients with Down syndrome. Acta Paediatr Taiwan. 2007;48:191-5.

77. Cutler AT, Benezra-Obeiter R, Brink SJ. Thyroid function in young children with Down syndrome. Am J Dis Child. 1986;140:479-83.

78. Livadas S, Xekouki P, Fouka F, Kanaka-Gantenbein C, Kaloumenou I, Mavrou A, et al. Prevalence of thyroid dysfunction in Turner's syndrome: a long-term follow-up study and brief literature review. Thyroid. 2005;15:1061-6.

79. Fukuda I, Hizuka N, Kurimoto M, Morita J, Tanaka S, Yamakado Y, et al. Autoimmune thyroid diseases in 65 Japanese women with Turner syndrome. Endocr J. 2009;56:983-6.

80. Mortensen KH, Cleemann L, Hjerrild BE, Nexo E, Locht H, Jeppesen EM, et al. Increased prevalence of autoimmunity in Turner syndrome--influence of age. Clin Exp Immunol. 2009;156:205-10.

81. Medeiros CC, Marini SH, Baptista MT, Guerra G Jr., MacielGuerra AT. Turner's syndrome and thyroid disease: a transverse study of pediatric patients in Brazil. J Pediatr Endocrinol Metab. 2000;13:357-62.

82. Chiovato L, Larizza $D$, Bendinelli G, Tonacchera M, Marino M, Mammoli $\mathrm{C}$, et al. Autoimmune hypothyroidism and hyperthyroidism in patients with Turner's syndrome. Eur J Endocrinol. 1996;134:568-75.

83. Filosa A, Di Maio S, Aloj G, Acampora C. Longitudinal study on thyroid function in patients with thalassemia major. J Pediatr Endocrinol Metab. 2006;19:1397-404.

84. Chan JC, Liu HS, Kho BC, Lau TK, Li VL, Chan FH, et al. Pattern of thyroid autoimmunity in chinese patients with pernicious anemia. Am J Med Sci. 2009;337:432-7.

85. Vitale G, Fatti LM, Prolo S, Girola A, Caraglia M, Marra M, et al. Screening for hypothyroidism in older hospitalized patients with anemia: a new insight into an old disease. J Am Geriatr Soc. 2010;58:1825-7. 
86. Vilar L, Freitas MC, Naves LA, Casulari LA, Azevedo M, Montenegro $\mathrm{R} \mathrm{Jr}$, et al. Diagnosis and management of hyperprolactinemia: results of a Brazilian multicenter study with 1234 patients. J Endocrinol Invest. 2008;31:436-44.

87. Lazarus $\mathrm{JH}$. The effects of lithium therapy on thyroid and thyrotropin-releasing hormone. Thyroid. 1998;8:909-13.

88. Bocchetta A, Bernardi F, Burrai C, Pedditzi M, Loviselli A, Velluzzi $F$, et al. The course of thyroid abnormalities during lithium treatment: a two-year follow-up study. Acta Psychiatr Scand. 1992;86:38-41.

89. van Melick EJ, Wilting I, Meinders AE, EgbertsTC. Prevalence and determinants of thyroid disorders in elderly patients with affective disorders: lithium and nonlithium patients. Am J Geriatr Psychiatry. 2010;18:395-403.

90. Mammen JS, Ghazarian SR, Pulkstenis E, Subramanian GM, Rosen A, Ladenson PW. Phenotypes of interferon-alpha-induced thyroid dysfunction among patients treated for hepatitis $\mathrm{C}$ are associated with pretreatment serum TSH and female sex. J Clin Endocrinol Metab. 2012;97:3270-6.

91. Clemons J, Gao D, Naam M, Breaker K, Garfield D, Flaig TW. Thyroid dysfunction in patients treated with sunitinib or sorafenib. Clin Genitourin Cancer. 2012;10(4):225-31.

92. Bogazzi F, Tomisti L, Bartalena L, Aghini-Lombardi F, Martino E. Amiodarone and the thyroid: a 2012 update. J Endocrinol Invest. 2012;35:340-8.

93. Pazin-Filho A, de Jesus AM, Magalhaes PK, Melato LH, Campos $D$, Maciel BC, et al. How frequently should a patient taking amiodarone be screened for thyroid dysfunction? Braz J Med Biol Res. 2009;42:744-9.

94. Ahmed S, Van Gelder IC, Wiesfeld AC, Van Veldhuisen DJ, Links TP. Determinants and outcome of amiodarone-associated thyroid dysfunction. Clin Endocrinol (Oxf). 2011;75:388-94.

95. Harjai KJ, Licata AA. Effects of amiodarone on thyroid function. Ann Intern Med. 1997;126:63-73.

96. Grundy S. 2002 Third Report of the National Cholesterol Education Program (NCEP) Expert Panel on Detection, Evaluation, and Treatment of High Blood Cholesterol in Adults (Adult Treatment Panel III) Final Report. Available at: http://www.nhlbi.nih.gov/ guidelines/cholesterol/atp3full.pdf. Accessed: Nov 21, 2012.

97. Tagami T, Kimura H, Ohtani S, Tanaka T, Hata S, Saito M, et al. Multi-center study on the prevalence of hypothyroidism in patients with hypercholesterolemia. Endocr J. 2011;58:449-57.

98. Almeida OP, Alfonso H, Flicker L, Hankey G, Chubb SA, Yeap BB. Thyroid hormones and depression: the Health in Men study. Am J Geriatr Psychiatry. 2011;19:763-70.

99. de Jongh RT, Lips P, van Schoor NM, Rijs KJ, Deeg DJ, Comijs $\mathrm{HC}$, et al. Endogenous subclinical thyroid disorders, physical and cognitive function, depression, and mortality in older individuals. Eur J Endocrinol. 2011;165:545-54.

100. Gussekloo J, van Exel E, de Craen AJ, Meinders AE, Frolich M, Westendorp RG. Thyroid status, disability and cognitive function, and survival in old age. JAMA. 2004;292:2591-9.

101. van de Ven AC, Muntjewerff JW, Netea-Maier RT, de Vegt F, Ross HA, Sweep FC, et al. Association between thyroid function, thyroid autoimmunity, and state and trait factors of depression. Acta Psychiatr Scand. 2012;126:377-84.

102. Biondi B. Mechanisms in endocrinology: heart failure and thyroid dysfunction. Eur J Endocrinol. 2012;167:609-18.

103. Gencer B, ColletTH, Virgini V, Bauer DC, Gussekloo J, Cappola AR, et al. Subclinical thyroid dysfunction and the risk of heart failure events: an individual participant data analysis from 6 prospective cohorts. Circulation. 2012;126:1040-9.

104. Jessup M, Abraham WT, Casey DE, Feldman AM, Francis GS, Ganiats TG, et al. 2009 focused update: ACCF / AHA Guidelines for the Diagnosis and Management of Heart Failure in Adults: a report of the American College of Cardiology Foundation/American Heart Association Task Force on Practice Guidelines: developed in collaboration with the International Society for Heart and Lung Transplantation. Circulation. 2009;119:1977-2016.

105. Spencer C, Petrovic I, Fatemi S. Current thyroglobulin autoantibody $(\operatorname{Tg} A b)$ assays often fail to detect interfering $\operatorname{TgAb}$ that can result in the reporting of falsely low/undetectable serum Tg IMA values for patients with differentiated thyroid cancer. J Clin Endocrinol Metab. 2011;96:1283-91.

106. O'Leary PC, Feddema PH, Michelangeli VP, Leedman PJ, Chew $\mathrm{GT}$, Knuiman $\mathrm{M}$, et al. Investigations of thyroid hormones and antibodies based on a community health survey: the Busselton thyroid study. Clin Endocrinol (Oxf). 2006;64:97-104.

107. Vanderpump MP, Tunbridge WM, French JM, Appleton D, Bates D, Clark $\mathrm{F}$, et al.The incidence of thyroid disorders in the community: a twenty-year follow-up of the Whickham Survey. Clin Endocrinol (Oxf). 1995;43:55-68.

108. Vejbjerg $P$, Knudsen N, Perrild H, Laurberg P, Pedersen IB, Rasmussen $L B$, et al. The association between hypoechogenicity or irregular echo pattern at thyroid ultrasonography and thyroid function in the general population. Eur J Endocrinol. 2006;155:547-52.

109. Pedersen OM, Aardal NP, Larssen TB, Varhaug JE, Myking O, Vik$\mathrm{Mo} \mathrm{H}$. The value of ultrasonography in predicting autoimmune thyroid disease. Thyroid. 2000;10:251-9.

110. Ericsson UB, Christensen SB, Thorell JI. A high prevalence of thyroglobulin autoantibodies in adults with and without thyroid disease as measured with a sensitive solid-phase immunosorbent radioassay. Clin Immunol Immunopathol. 1985;37:154-62.

111. Tozzoli R, Villalta D, Kodermaz G, Bagnasco M, Tonutti E, Bizzaro $\mathrm{N}$. Autoantibody profiling of patients with autoimmune thyroid disease using a new multiplexed immunoassay method. Clin Chem Lab Med. 2006;44:837-42.

112. Kuijpens JL, De Hann-Meulman M, Vader HL, Pop VJ, Wiersinga WM, Drexhage HA. Cell-mediated immunity and postpartum thyroid dysfunction: a possibility for the prediction of disease? J Clin Endocrinol Metab. 1998;83:1959-66.

113. Fung HY, Kologlu M, Collison $K$, John R, Richards CJ, Hall R, et al. Postpartum thyroid dysfunction in Mid Glamorgan. Br Med J (Clin Res Ed). 1988;296:241-4.

114. Gilmour J, Brownlee Y, Foster P, Geekie C, Kelly P, Robertson S, et al. The quantitative measurement of autoantibodies to thyroglobulin and thyroid peroxidase by automated microparticle based immunoassays in Hashimoto's disease, Graves' disease and a follow-up study on postpartum thyroid disease. Clin Lab. 2000:46:57-61.

115. Weetman AP, McGregor AM. Autoimmune thyroid disease: further developments in our understanding. Endocr Rev. 1994;15:788-830.

116. Hamada N, Noh JY, Okamoto Y, Ueda M, Konishi T, Fujisawa T, et al. Measuring thyroglobulin autoantibodies by sensitive assay is important for assessing the presence of thyroid autoimmunity in areas with high iodine intake. Endocr J. 2010;57:645-9.

117. Giovanella L. Is simultaneous measurement of anti-thyroid peroxidase and anti-thyroglobulin antibodies clinically useful in patients with thyroid dysfunction? Clin Chem Lab Med. 2007;45:263.

118. Anderson L, Middleton WD, Teefey SA, Reading CC, Langer JE, DesserT, et al. Hashimoto thyroiditis: Part 1, sonographic analysis of the nodular form of Hashimoto thyroiditis. AJR Am J Roentgenol. 2010;195:208-15.

119. Raber W, Gessl A, Nowotny P, Vierhapper H. Thyroid ultrasound versus antithyroid peroxidase antibody determination: a cohort study of four hundred fifty-one subjects. Thyroid. 2002;12:725-31.

120. Marcocci C, Vitti P, Cetani F, Catalano F, Concetti R, Pinchera A. Thyroid ultrasonography helps to identify patients with diffuse lymphocytic thyroiditis who are prone to develop hypothyroidism. J Clin Endocrinol Metab. 1991;72:209-13. 
121. Rosario PW, Bessa B, Valadao MM, Purisch S. Natural history of mild subclinical hypothyroidism: prognostic value of ultrasound. Thyroid. 2009;19:9-12.

122. Meyerovitch J, Rotman-Pikielny P, Sherf M, Battat E, LevyY, Surks MI. Serum thyrotropin measurements in the community: fiveyear follow-up in a large network of primary care physicians. Arch Intern Med. 2007;167:1533-8.

123. Walsh JP, Bremner AP, Feddema P, Leedman PJ, Brown SJ, $O$ 'Leary P. Thyrotropin and thyroid antibodies as predictors of hypothyroidism: a 13-year, longitudinal study of a communitybased cohort using current immunoassay techniques. J Clin Endocrinol Metab. 2010;95:1095-104.

124. Diez JJ, Iglesias P. Spontaneous subclinical hypothyroidism in patients older than 55 years: an analysis of natural course and risk factors for the development of overt thyroid failure. J Clin Endocrinol Metab. 2004;89:4890-7.

125. Parle JV, Franklyn JA, Cross KW, Jones SC, Sheppard MC. Prevalence and follow-up of abnormal thyrotrophin (TSH) concentrations in the elderly in the United Kingdom. Clin Endocrinol (Oxf). 1991;34:77-83.

126. Somwaru LL, Rariy CM, Arnold AM, Cappola AR. The natural history of subclinical hypothyroidism in the elderly: the cardiovascular health study. J Clin Endocrinol Metab. 2012;97:1962-9.

127. Bell RJ, Rivera-Woll L, Davison SL, Topliss DJ, Donath S, Davis SR. Well-being, health-related quality of life and cardiovascular disease risk profile in women with subclinical thyroid disease - a community-based study. Clin Endocrinol (Oxf). 2007;66:548-56.

128. Ceresini G, Lauretani F, Maggio M, Ceda GP, Morganti S, Usberti $\mathrm{E}$, et al. Thyroid function abnormalities and cognitive impairment in elderly people: results of the Invecchiare in Chianti study. J Am Geriatr Soc. 2009;57:89-93.

129. Roberts LM, Pattison H, Roalfe A, Franklyn J, Wilson S, Hobbs $F D$, et al. Is subclinical thyroid dysfunction in the elderly associated with depression or cognitive dysfunction? Ann Intern Med. 2006;145:573-81.

130. Almeida C, Vaisman M, Costa AJ, Reis FA, Reuters V, Teixeira P, et al. Are neuropsychological changes relevant in subclinical hypothyroidism? Arq Bras Endocrinol Metabol. 2007;51:606-11.

131. Teixeira Pde F, Reuters VS, Almeida CP, Ferreira MM, Wagman MB, Reis FA, et al. [Evaluation of clinical and psychiatric symptoms in sub clinical hypothyroidism]. Rev Assoc Med Bras. 2006;52:222-8.

132. Razvi S, Ingoe L, Keeka G, Oates C, McMillan C, Weaver JU. The beneficial effect of L-thyroxine on cardiovascular risk factors, endothelial function, and quality of life in subclinical hypothyroidism: randomized, crossover trial. J Clin Endocrinol Metab. 2007;92:1715-23.

133. Jorde R, Waterloo K, Storhaug H, Nyrnes A, Sundsfjord J, Jenssen TG. Neuropsychological function and symptoms in subjects with subclinical hypothyroidism and the effect of thyroxine treatment. J Clin Endocrinol Metab. 2006;91:145-53.

134. Parle J, Roberts L, Wilson S, Pattison H, Roalfe A, Haque MS, et al. A randomized controlled trial of the effect of thyroxine replacement on cognitive function in community-living elderly subjects with subclinical hypothyroidism: the Birmingham ElderlyThyroid study. J Clin Endocrinol Metab. 2010;95:3623-32.

135. Duntas LH, Brenta G. The effect of thyroid disorders on lipid levels and metabolism. Med Clin North Am. 2012;96:269-81.

136. Pearce EN. Update in lipid alterations in subclinical hypothyroidism. J Clin Endocrinol Metab. 2012;97:326-33.

137. Kanaya AM, Harris F, Volpato S, Perez-Stable EJ, Harris T, Bauer DC. Association between thyroid dysfunction and total cholesterol level in an older biracial population: the health, aging and body composition study. Arch Intern Med. 2002;162:773-9.

138. Walsh JP, Bremner AP, Bulsara MK, O'Leary P, Leedman PJ, Feddema $P$, et al. Subclinical thyroid dysfunction as a risk factor for cardiovascular disease. Arch Intern Med. 2005;165:2467-72.
139. Hueston WJ, Pearson WS. Subclinical hypothyroidism and the risk of hypercholesterolemia. Ann Fam Med. 2004;2:351-5.

140. Sgarbi JA, Matsumura LK, KasamatsuTS, Ferreira SR, Maciel RM. Subclinical thyroid dysfunctions are independent risk factors for mortality in a 7.5-year follow-up: the Japanese-Brazilian thyroid study. Eur J Endocrinol. 2010;162:569-77.

141. Danese MD, Ladenson PW, Meinert CL, Powe NR. Clinical review 115: effect of thyroxine therapy on serum lipoproteins in patients with mild thyroid failure: a quantitative review of the literature. $J$ Clin Endocrinol Metab. 2000;85:2993-3001.

142. Villar HC, Saconato H, Valente O, Atallah AN. Thyroid hormone replacement for subclinical hypothyroidism. Cochrane Database Syst Rev. 2007:CD003419.

143. Iqbal A, Jorde R, Figenschau Y. Serum lipid levels in relation to serum thyroid-stimulating hormone and the effect of thyroxine treatment on serum lipid levels in subjects with subclinical hypothyroidism: the Tromso Study. J Intern Med. 2006;260:53-61.

144. Mikhail GS, Alshammari SM, Alenezi MY, Mansour M, Khalil NA. Increased atherogenic low-density lipoprotein cholesterol in untreated subclinical hypothyroidism. Endocr Pract. 2008;14:570-5.

145. Teixeira Pde F, Reuters VS, Ferreira MM, Almeida CP, Reis FA, Buescu $A$, et al. Lipid profile in different degrees of hypothyroidism and effects of levothyroxine replacement in mild thyroid failure. Transl Res. 2008;151:224-31.

146. CaiY, RenY, Shi J. Blood pressure levels in patients with subclinical thyroid dysfunction: a meta-analysis of cross-sectional data. Hypertens Res. 2011;34:1098-105.

147. CaiYF, Shi JP. [Meta analysis on the relationship between subclinical hypothyroidism and the levels of systolic blood pressure.]. Zhonghua Liu Xing Bing Xue Za Zhi. 2011;32:55-9.

148. Biondi B, Fazio S, Palmieri EA, Carella C, Panza N, Cittadini A, et al. Left ventricular diastolic dysfunction in patients with subclinical hypothyroidism. J Clin Endocrinol Metab. 1999;84:2064-7.

149. Brenta G, Mutti LA, Schnitman M, Fretes O, Perrone A, Matute ML. Assessment of left ventricular diastolic function by radionuclide ventriculography at rest and exercise in subclinical hypothyroidism, and its response to L-thyroxine therapy. Am J Cardiol. 2003;91:1327-30.

150. Monzani F, Di Bello V, Caraccio N, Bertini A, Giorgi D, Giusti C, et al. Effect of levothyroxine on cardiac function and structure in subclinical hypothyroidism: a double blind, placebo-controlled study. J Clin Endocrinol Metab. 2001;86:1110-5.

151. Yazici M, Gorgulu S, Sertbas Y, Erbilen E, Albayrak S, Yildiz O, et al. Effects of thyroxin therapy on cardiac function in patients with subclinical hypothyroidism: index of myocardial performance in the evaluation of left ventricular function. Int $\mathrm{J}$ Cardiol. 2004;95:135-43.

152. Vitale G, Galderisi M, Lupoli GA, Celentano A, Pietropaolo I, Parenti $\mathrm{N}$, et al. Left ventricular myocardial impairment in subclinical hypothyroidism assessed by a new ultrasound tool: pulsed tissue Doppler. J Clin Endocrinol Metab. 2002;87:4350-5.

153. Di Bello V, Monzani F, Giorgi D, Bertini A, Caraccio N, Valenti G, et al. Ultrasonic myocardial textural analysis in subclinical hypothyroidism. J Am Soc Echocardiogr. 2000;13:832-40.

154. Aghini-Lombardi F, Di Bello V, Talini E, Di Cori A, Monzani F, Antonangeli $L$, et al. Early textural and functional alterations of left ventricular myocardium in mild hypothyroidism. Eur J Endocrinol. 2006;155:3-9.

155. Pearce EN, Yang Q, Benjamin EJ, Aragam J, Vasan RS. Thyroid function and left ventricular structure and function in the Framingham Heart Study. Thyroid. 2010;20:369-73.

156. Arem R, Rokey R, Kiefe C, Escalante DA, Rodriguez A. Cardiac systolic and diastolic function at rest and exercise in subclinical hypothyroidism: effect of thyroid hormone therapy. Thyroid. 1996;6:397-402. 
157. Franzoni F, Galetta F, Fallahi P, Tocchini L, Merico G, Braccini L, et al. Effect of L-thyroxine treatment on left ventricular function in subclinical hypothyroidism. Biomed Pharmacother. 2006;60:431-6.

158. Rodondi N, Newman AB, Vittinghoff E, de Rekeneire N, Satterfield S, HarrisTB, et al. Subclinical hypothyroidism and the risk of heart failure, other cardiovascular events, and death. Arch Intern Med. 2005;165:2460-6.

159. Rodondi N, Bauer DC, Cappola AR, Cornuz J, Robbins J, Fried LP, et al. Subclinical thyroid dysfunction, cardiac function, and the risk of heart failure. The Cardiovascular Health study. J Am Coll Cardiol. 2008;52:1152-9.

160. Nanchen D, Gussekloo J, Westendorp RG, Stott DJ, Jukema JW, Trompet S, et al. Subclinical thyroid dysfunction and the risk of heart failure in older persons at high cardiovascular risk. J Clin Endocrinol Metab. 2012;97:852-61.

161. Imaizumi M, Akahoshi M, Ichimaru S, Nakashima E, Hida A, Soda $\mathrm{M}$, et al. Risk for ischemic heart disease and all-cause mortality in subclinical hypothyroidism. J Clin Endocrinol Metab. 2004;89:3365-70.

162. lervasi G, Molinaro S, Landi P,Taddei MC, Galli E, Mariani F, et al. Association between increased mortality and mild thyroid dysfunction in cardiac patients. Arch Intern Med. 2007;167:1526-32.

163. Asvold BO, Bjoro T, Nilsen TI, Gunnell D, Vatten LJ. Thyrotropin levels and risk of fatal coronary heart disease: the HUNT study. Arch Intern Med. 2008;168:855-60.

164. Boekholdt SM, Titan SM, Wiersinga WM, Chatterjee K, Basart DC, Luben R, et al. Initial thyroid status and cardiovascular risk factors: the EPIC-Norfolk prospective population study. Clin Endocrinol (Oxf). 2010;72:404-10.

165. Cappola AR, Fried LP, Arnold AM, Danese MD, Kuller LH, Burke $\mathrm{GL}$, et al. Thyroid status, cardiovascular risk, and mortality in older adults. JAMA. 2006;295:1033-41.

166. Razvi S, Weaver JU, Vanderpump MP, Pearce SH. The incidence of ischemic heart disease and mortality in people with subclinical hypothyroidism: reanalysis of the Whickham Survey cohort. J Clin Endocrinol Metab. 2010;95:1734-40.

167. McQuade C, Skugor M, Brennan DM, Hoar B, Stevenson C, Hoogwerf BJ. Hypothyroidism and moderate subclinical hypothyroidism are associated with increased all-cause mortality independent of coronary heart disease risk factors: a PreCIS database study. Thyroid. 2011;21:837-43.

168. Rodondi N, Aujesky D, Vittinghoff E, Cornuz J, Bauer DC. Subclinical hypothyroidism and the risk of coronary heart disease: a meta-analysis. Am J Med. 2006;119:541-51.

169. Singh S, Duggal J, Molnar J, Maldonado F, Barsano CP, Arora R. Impact of subclinical thyroid disorders on coronary heart disease, cardiovascular and all-cause mortality: a meta-analysis. Int J Cardiol. 2008;125:41-8.

170. Ochs N, Auer R, Bauer DC, Nanchen D, Gussekloo J, Cornuz J, et al. Meta-analysis: subclinical thyroid dysfunction and the risk for coronary heart disease and mortality. Ann Intern Med. 2008;148:832-45.

171. Razvi S, Shakoor A, Vanderpump M, Weaver JU, Pearce SH. The influence of age on the relationship between subclinical hypothyroidism and ischemic heart disease: a metaanalysis. J Clin Endocrinol Metab. 2008;93:2998-3007.

172. Volzke H, Friedrich N, Schipf S, Haring R, Ludemann J, Nauck $M$, et al. Association between serum insulin-like growth factor-I levels and thyroid disorders in a population-based study. J Clin Endocrinol Metab. 2007;92:4039-45.

173. Haentjens P, Van Meerhaeghe A, Poppe K, Velkeniers B. Subclinical thyroid dysfunction and mortality: an estimate of relative and absolute excess all-cause mortality based on time-to-event data from cohort studies. Eur J Endocrinol. 2008;159:329-41.
174. Rodondi N, den Elzen WP, Bauer DC, Cappola AR, Razvi S, Walsh $\mathrm{JP}$, et al. Subclinical hypothyroidism and the risk of coronary heart disease and mortality. JAMA. 2010;304:1365-74.

175. Razvi S, Weaver JU, Butler TJ, Pearce SH. Levothyroxine treatment of subclinical hypothyroidism, fatal and nonfatal cardiovascular events, and mortality. Arch Intern Med. 2012;172:811-7.

176. Atzmon G, Barzilai N, Surks MI, Gabriely I. Genetic predisposition to elevated serum thyrotropin is associated with exceptional longevity. J Clin Endocrinol Metab. 2009;94:4768-75.

177. Formiga F, Ferrer $A$. Thyrotropin serum values and 3-year mortality in nonagenarians. J Gerontol A Biol Sci Med Sci. 2010; 65:12501 ; author reply 1252-3.

178. Surks MI, Boucai L. Age- and race-based serum thyrotropin reference limits. J Clin Endocrinol Metab. 2010;95:496-502.

179. Cooper DS, Halpern R, Wood LC, Levin AA, Ridgway EC. L-Thyroxine therapy in subclinical hypothyroidism. A double-blind, placebo-controlled trial. Ann Intern Med. 1984;101:18-24.

180. Fish LH, Schwartz HL, Cavanaugh J, Steffes MW, Bantle JP, Oppenheimer JH. Replacement dose, metabolism, and bioavailability of levothyroxine in the treatment of hypothyroidism. Role of triiodothyronine in pituitary feedback in humans. N Engl J Med. 1987; 316:764-70.

181. Williams GR, Bassett JH. Deiodinases: the balance of thyroid hormone: local control of thyroid hormone action: role of type 2 deiodinase. J Endocrinol. 2011;209:261-72.

182. Escobar-Morreale HF, Obregon MJ, Escobar del Rey F, Morreale de Escobar G. Replacement therapy for hypothyroidism with thyroxine alone does not ensure euthyroidism in all tissues, as studied in thyroidectomized rats. J Clin Invest. 1995;96:2828-38.

183. Bunevicius R, Kazanavicius G, Zalinkevicius R, Prange AJ Jr. Effects of thyroxine as compared with thyroxine plus triiodothyronine in patients with hypothyroidism. N Engl J Med. 1999;340:424-9.

184. Panicker V, Saravanan P, Vaidya B, Evans J, Hattersley AT, Frayling $\mathrm{TM}$, et al. Common variation in the DIO2 gene predicts baseline psychological well-being and response to combination thyroxine plus triiodothyronine therapy in hypothyroid patients. J Clin Endocrinol Metab. 2009;94:1623-9.

185. Grozinsky-Glasberg S, Fraser A, Nahshoni E, Weizman A, Leibovici $L$. Thyroxine-triiodothyronine combination therapy versus thyroxine monotherapy for clinical hypothyroidism: meta-analysis of randomized controlled trials. J Clin Endocrinol Metab. 2006;91:2592-9.

186. Ma C, Xie J, Huang X, Wang G, Wang Y, Wang X, et al. Thyroxine alone or thyroxine plus triiodothyronine replacement therapy for hypothyroidism. Nucl Med Commun. 2009;30:586-93.

187. Bach-Huynh TG, Nayak B, Loh J, Soldin S, Jonklaas J. Timing of levothyroxine administration affects serum thyrotropin concentration. J Clin Endocrinol Metab. 2009;94:3905-12.

188. Bolk N, Visser TJ, Nijman J, Jongste IJ, Tijssen JG, Berghout A. Effects of evening vs morning levothyroxine intake: a randomized double-blind crossover trial. Arch Intern Med. 2010;170:19962003.

189. Rajput R, Chatterjee S, Rajput M. Can levothyroxine be taken as evening dose? Comparative evaluation of morning versus evening dose of levothyroxine in treatment of hypothyroidism. JThyroid Res. 2011;2011:505239.

190. Devdhar M, Drooger R, Pehlivanova M, Singh G, Jonklaas J. Levothyroxine replacement doses are affected by gender and weight, but not age. Thyroid. 2011;21:821-7.

191. Roos A, Linn-Rasker SP, van Domburg RT, Tijssen JP, Berghout A. The starting dose of levothyroxine in primary hypothyroidism treatment: a prospective, randomized, double-blind trial. Arch Intern Med. 2005;165:1714-20.

192. Biondi B. Should we treat all subjects with subclinical thyroid disease the same way? Eur J Endocrinol. 2008;159:343-5. 
193. Klein I, Danzi S. Thyroid disease and the heart. Circulation. 2007;116:1725-35.

194. Martins RM, Fonseca RH, Duarte MM, Reuters VS, Ferreira MM, Almeida C, et al. Impact of subclinical hypothyroidism treatment in systolic and diastolic cardiac function. Arq Bras Endocrinol Metabol. 2011;55:460-7.

195. Turner MR, Camacho X, Fischer HD, Austin PC, Anderson GM, Rochon PA, et al. Levothyroxine dose and risk of fractures in older adults: nested case-control study. BMJ. 2011;342:d2238.

196. Olveira G, Almaraz MC, Soriguer F, Garriga MJ, Gonzalez-Romero $S$, Tinahones $F$, et al. Altered bioavailability due to changes in the formulation of a commercial preparation of levothyroxine in patients with differentiated thyroid carcinoma. Clin Endocrinol (Oxf). 1997;46:707-11.

197. Hennessey JV, Malabanan AO, Haugen BR, Levy EG. Adverse event reporting in patients treated with levothyroxine: results of the pharmacovigilance task force survey of the american thyroid association, american association of clinical endocrinologists, and the endocrine society. Endocr Pract. 2010;16:357-70.

198. Yassa $L$, Marqusee E, Fawcett R, Alexander EK. Thyroid hormone early adjustment in pregnancy (the THERAPY) trial. J Clin Endocrinol Metab. 2010;95:3234-41.

199. Ojomo KA, Schneider DF, Reiher AE, Lai N, Schaefer S, Chen H, et al. Using body mass index to predict optimal thyroid dosing after thyroidectomy. J Am Coll Surg. 2013;216:454-60.

200. Ward LS. The difficult patient: drug interaction and the influence of concomitant diseases on the treatment of hypothyroidism. Arq Bras Endocrinol Metabol. 2010;54:435-42.

201. Hannemann A, Friedrich N, Haring R, Krebs A, Volzke H, Alte D, et al. Thyroid function tests in patients taking thyroid medication in Germany: results from the population-based Study of Health in Pomerania (SHIP). BMC Res Notes. 2010;3:227.

202. Okosieme OE, Belludi G, Spittle K, Kadiyala R, Richards J. Adequacy of thyroid hormone replacement in a general population. QJM. 2011;104:395-401.

203. Zamfirescu I, Carlson HE. Absorption of levothyroxine when coadministered with various calcium formulations. Thyroid. 2011;21:483-6.

204. Centanni M, Gargano L, Canettieri G, Viceconti N, Franchi A, Delle Fave G, et al. Thyroxine in goiter, Helicobacter pylori infection, and chronic gastritis. N Engl J Med. 2006;354:1787-95.

205. Radaeli Rde F, Diehl LA. Increased levothyroxine requirement in a woman with previously well-controlled hypothyroidism and intestinal giardiasis. Arq Bras Endocrinol Metabol. 2011;55:81-4.

206. Abdulrahman RM, Verloop H, Hoftijzer H, Verburg E, Hovens GC, Corssmit EP, et al. Sorafenib-induced hypothyroidism is associated with increased type 3 deiodination. J Clin Endocrinol Metab. 2010;95:3758-62.

207. StrykerTD, Molitch ME. Reversible hyperthyrotropinemia, hyperthyroxinemia, and hyperprolactinemia due to adrenal insufficiency. Am J Med. 1985;79:271-6.

208. Abdullatif HD, Ashraf AP. Reversible subclinical hypothyroidism in the presence of adrenal insufficiency. Endocr Pract. 2006;12:572.

209. Louwerens M, Appelhof BC, Verloop H, Medici M, Peeters RP, VisserTJ, et al. Fatigue and fatigue-related symptoms in patients treated for different causes of hypothyroidism. Eur J Endocrinol. 2012;167:809-15.

210. Ott J, Promberger R, Kober F, Neuhold N, Tea M, Huber JC, et al. Hashimoto's thyroiditis affects symptom load and quality of life unrelated to hypothyroidism: a prospective case-control study in women undergoing thyroidectomy for benign goiter. Thyroid. 2011;21:161-7.

211. Walsh JP, Ward LC, Burke V, Bhagat Cl, Shiels L, Henley D, et al. Small changes in thyroxine dosage do not produce measurable changes in hypothyroid symptoms, well-being, or quality of life: results of a double-blind, randomized clinical trial. J Clin Endocrinol Metab. 2006;91:2624-30.

212. Boeving A, Paz-Filho G, Radominski RB, Graf H, Amaral de Carvalho G. Low-normal or high-normal thyrotropin target levels during treatment of hypothyroidism: a prospective, comparative study. Thyroid. 2011;21:355-60.

213. Mathew V, Misgar RA, Ghosh S, Mukhopadhyay P, Roychowdhury $P$, Pandit $K$, et al. Myxedema coma: a new look into an old crisis. JThyroid Res. 2011;2011:493462.

214. Wartofsky L. Myxedema coma. Endocrinol Metab Clin North Am. 2006;35:687-98, vii-viii.

215. Rodriguez I, Fluiters E, Perez-Mendez LF, Luna R, Paramo C, Garcia-Mayor RV. Factors associated with mortality of patients with myxoedema coma: prospective study in 11 cases treated in a single institution. J Endocrinol. 2004;180:347-50.

216. Dutta P, Bhansali A, Masoodi SR, Bhadada S, Sharma N, Rajput R. Predictors of outcome in myxoedema coma: a study from a tertiary care centre. Crit Care. 2008;12:R1.

217. Arlot S, Debussche $X$, Lalau JD, Mesmacque A, Tolani M, Quichaud $J$, et al. Myxoedema coma: response of thyroid hormones with oral and intravenous high-dose L-thyroxine treatment. Intensive Care Med. 1991;17:16-8.

218. Savage MW, Mah PM, Weetman AP, Newell-Price J. Endocrine emergencies. Postgrad Med J. 2004;80:506-15.

219. Benhadi N, Wiersinga WM, Reitsma JB, Vrijkotte TG, van der Wal MF, Bonsel GJ. Ethnic differences in TSH but not in free T4 concentrations or TPO antibodies during pregnancy. Clin Endocrinol (Oxf). 2007;66:765-70.

220. Stagnaro-Green A, Abalovich M, Alexander E, Azizi F, Mestman J, Negro R, et al. Guidelines of the American Thyroid Association for the diagnosis and management of thyroid disease during pregnancy and postpartum. Thyroid. 2011;21:1081-125.

221. Haddow JE, Knight GJ, Palomaki GE, McClain MR, Pulkkinen AJ. The reference range and within-person variability of thyroid stimulating hormone during the first and second trimesters of pregnancy. J Med Screen. 2004;11:170-4.

222. Panesar NS, Li CY, Rogers MS. Reference intervals for thyroid hormones in pregnant Chinese women. Ann Clin Biochem. 2001;38:329-32.

223. Stricker R, Echenard M, Eberhart R, Chevailler MC, Perez V, Quinn FA. Evaluation of maternal thyroid function during pregnancy: the importance of using gestational age-specific reference intervals. Eur J Endocrinol. 2007;157:509-14.

224. Kahric-Janicic N, Soldin SJ, Soldin OP, West T, Gu J, Jonklaas J. Tandem mass spectrometry improves the accuracy of free thyroxine measurements during pregnancy. Thyroid. 2007;17:303-11.

225. Lee RH, Spencer CA, Mestman JH, Miller EA, Petrovic I, Braverman LE, et al. FreeT4 immunoassays are flawed during pregnancy. Am J Obstet Gynecol. 2009;200:260 e1-6.

226. Begg CB. Biases in the assessment of diagnostic tests. Stat Med. 1987;6:411-23.

227. Glinoer D. The systematic screening and management of hypothyroidism and hyperthyroidism during pregnancy. Trends Endocrinol Metab. 1998;9:403-11.

228. Klein RZ, Haddow JE, Faix JD, Brown RS, Hermos RJ, Pulkkinen $A$, et al. Prevalence of thyroid deficiency in pregnant women. Clin Endocrinol (Oxf). 1991;35:41-6.

229. Abalovich M, Gutierrez S, Alcaraz G, Maccallini G, Garcia A, Levalle $O$. Overt and subclinical hypothyroidism complicating pregnancy. Thyroid. 2002;12:63-8.

230. Haddow JE, Palomaki GE, Allan WC, Williams JR, Knight GJ, Gagnon J, et al. Maternal thyroid deficiency during pregnancy and subsequent neuropsychological development of the child. $\mathrm{N} \mathrm{Engl}$ J Med. 1999;341:549-55. 
231. Allan WC, Haddow JE, Palomaki GE, Williams JR, Mitchell ML, Hermos RJ, et al. Maternal thyroid deficiency and pregnancy complications: implications for population screening. J Med Screen. 2000;7:127-30.

232. Lazarus JH, Bestwick JP, Channon S, Paradice R, Maina A, Rees R, et al. Antenatal thyroid screening and childhood cognitive function. N Engl J Med. 2012;366:493-501.

233. Negro R, Formoso G, MangieriT, Pezzarossa A, Dazzi D, Hassan H. Levothyroxine treatment in euthyroid pregnant women with autoimmune thyroid disease: effects on obstetrical complications. $\mathrm{J}$ Clin Endocrinol Metab. 2006;91:2587-91.

234. Thangaratinam S, Tan A, Knox E, Kilby MD, Franklyn J, Coomarasamy $A$. Association between thyroid autoantibodies and miscarriage and preterm birth: meta-analysis of evidence. BMJ. 2011;342:d2616.

235. Sieiro Netto L, Medina Coeli C, Micmacher E, Mamede Da Costa S, Nazar L, Galvao D, et al. Influence of thyroid autoimmunity and maternal age on the risk of miscarriage. Am J Reprod Immunol. 2004;52:312-6.

236. Poppe $K$, Glinoer D, Tournaye $H$, Devroey $P$, van Steirteghem A, Kaufman L, et al. Assisted reproduction and thyroid autoimmunity: an unfortunate combination? J Clin Endocrinol Metab. 2003;88:4149-52.

237. Glinoer D, Riahi M, Grun JP, Kinthaert J. Risk of subclinical hypothyroidism in pregnant women with asymptomatic autoimmune thyroid disorders. J Clin Endocrinol Metab. 1994;79:197-204.

238. Casey BM, Dashe JS, Wells CE, McIntire DD, Byrd W, Leveno KJ, et al. Subclinical hypothyroidism and pregnancy outcomes. Obstet Gynecol 2005;105:239-45.

239. Negro R, Schwartz A, Gismondi R, Tinelli A, Mangieri T, StagnaroGreen $A$. Universal screening versus case finding for detection and treatment of thyroid hormonal dysfunction during pregnancy. J Clin Endocrinol Metab. 2010;95:1699-707.

240. Mannisto T, Vaarasmaki M, Pouta A, Hartikainen AL, Ruokonen A, Surcel HM, et al. Thyroid dysfunction and autoantibodies during pregnancy as predictive factors of pregnancy complications and maternal morbidity in later life. J Clin Endocrinol Metab. 2010;95:1084-94.

241. Dosiou C, Sanders GD, Araki SS, Crapo LM. Screening pregnant women for autoimmune thyroid disease: a cost-effectiveness analysis. Eur J Endocrinol. 2008;158:841-51.

242. Thung SF, Funai EF, Grobman WA. The cost-effectiveness of universal screening in pregnancy for subclinical hypothyroidism. Am J Obstet Gynecol. 2009;200:267e1-7.

243. Horacek J, Spitalnikova S, Dlabalova B, Malirova E, Vizda J, Svilias $I$, et al. Universal screening detects two-times more thyroid disorders in early pregnancy than targeted high-risk case finding. Eur J Endocrinol. 2010;163:645-50.

244. Dosiou C, Barnes J, Schwartz A, Negro R, Crapo L, StagnaroGreen A. Cost-effectiveness of universal and risk-based screening for autoimmune thyroid disease in pregnant women. J Clin Endocrinol Metab. 2012;97:1536-46.

245. Toulis KA, Goulis DG, Venetis CA, Kolibianakis EM, Negro R, Tarlatzis BC, et al. Risk of spontaneous miscarriage in euthyroid women with thyroid autoimmunity undergoing IVF: a meta-analysis. Eur J Endocrinol. 2010;162:643-52.

246. Poppe K, Glinoer D, Van Steirteghem A, Tournaye H, Devroey P, Schiettecatte J, et al. Thyroid dysfunction and autoimmunity in infertile women. Thyroid. 2002;12:997-1001.

247. Gerhard I, Becker T, Eggert-Kruse W, Klinga K, Runnebaum B. Thyroid and ovarian function in infertile women. Hum Reprod. 1991;6:338-45.

248. Stagnaro-Green A, Roman SH, Cobin RH, el-Harazy E, AlvarezMarfany M, Davies TF. Detection of at-risk pregnancy by means of highly sensitive assays for thyroid autoantibodies. JAMA. 1990;264:1422-5.

249. Prummel MF, Wiersinga WM. Thyroid autoimmunity and miscarriage. Eur J Endocrinol. 2004;150:751-5.

250. Negro R, Mangieri T, Coppola L, Presicce G, Casavola EC, Gismondi $\mathrm{R}$, et al. Levothyroxine treatment in thyroid peroxidase antibody-positive women undergoing assisted reproduction technologies: a prospective study. Hum Reprod. 2005;20:1529-33.

251. Kutteh WH, Yetman DL, Carr AC, Beck LA, Scott RT Jr. Increased prevalence of antithyroid antibodies identified in women with recurrent pregnancy loss but not in women undergoing assisted reproduction. Fertil Steril. 1999;71:843-8.

252. Pratt D, Novotny M, Kaberlein G, Dudkiewicz A, Gleicher N. Antithyroid antibodies and the association with non-organ-specific antibodies in recurrent pregnancy loss. Am J Obstet Gynecol. 1993;168:837-41.

253. Muller AF, Verhoeff A, Mantel MJ, Berghout A. Thyroid autoimmunity and abortion: a prospective study in women undergoing in vitro fertilization. Fertil Steril. 1999;71:30-4.

254. Iravani AT, Saeedi MM, Pakravesh J, Hamidi S, Abbasi M. Thyroid autoimmunity and recurrent spontaneous abortion in Iran: a case-control study. Endocr Pract. 2008;14:458-64.

255. Stagnaro-Green A, Glinoer D. Thyroid autoimmunity and the risk of miscarriage. Best Pract Res Clin Endocrinol Metab. 2004;18:167-81.

256. Klubo-Gwiezdzinska J, Burman KD, Van Nostrand D, Wartofsky L. Levothyroxine treatment in pregnancy: indications, efficacy, and therapeutic regimen. JThyroid Res. 2011;2011:843591.

257. Glinoer D. The regulation of thyroid function in pregnancy: pathways of endocrine adaptation from physiology to pathology. Endocr Rev. 1997; 18:404-33.

258. Barber KJ, Franklyn JA, McCabe CJ, Khanim FL, Bulmer JN, Whitley GS, et al. The in vitro effects of triiodothyronine on epidermal growth factor-induced trophoblast function. J Clin Endocrinol Metab. 2005;90:1655-61.

259. Oki N, Matsuo H, Nakago S, Murakoshi H, Laoag-Fernandez JB, Maruo T. Effects of 3,5,3'-triiodothyronine on the invasive potential and the expression of integrins and matrix metalloproteinases in cultured early placental extravillous trophoblasts. J Clin Endocrinol Metab. 2004;89:5213-21.

260. Rushworth FH, Backos M, Rai R, Chilcott IT, Baxter N, Regan L. Prospective pregnancy outcome in untreated recurrent miscarriers with thyroid autoantibodies. Hum Reprod. 2000;15:1637-9.

261. Ghafoor F, Mansoor M, MalikT, Malik MS, Khan AU, Edwards R, et al. Role of thyroid peroxidase antibodies in the outcome of pregnancy. J Coll Physicians Surg Pak. 2006;16:468-71.

262. lijima T, Tada H, Hidaka Y, Mitsuda N, Murata Y, Amino N. Effects of autoantibodies on the course of pregnancy and fetal growth. Obstet Gynecol. 1997; $90: 364-9$.

263. Negro R, Formoso G, Coppola L, Presicce G, MangieriT, Pezzarossa $A$, et al. Euthyroid women with autoimmune disease undergoing assisted reproduction technologies: the role of autoimmunity and thyroid function. J Endocrinol Invest. 2007;30:3-8.

264. Poppe K, Glinoer D, Tournaye H, Schiettecatte J, Devroey P, van Steirteghem A, et al. Impact of ovarian hyperstimulation on thyroid function in women with and without thyroid autoimmunity. J Clin Endocrinol Metab. 2004;89:3808-12.

265. Singh A, Dantas ZN, Stone SC, Asch RH. Presence of thyroid antibodies in early reproductive failure: biochemical versus clinical pregnancies. Fertil Steril. 1995;63:277-81.

266. Bagis T, Gokcel A, Saygili ES. Autoimmune thyroid disease in pregnancy and the postpartum period: relationship to spontaneous abortion. Thyroid. 2001;11:1049-53.

267. Lejeune B, Grun JP, de Nayer P, Servais G, Glinoer D. Antithyroid antibodies underlying thyroid abnormalities and miscar- 
riage or pregnancy induced hypertension. $\mathrm{Br} \mathrm{J}$ Obstet Gynaecol. 1993;100:669-72.

268. Sezer K, Kamel N, Unlu C, Celik HK. Impact of first trimester and postpartum period thyroid autoantibodies on abortus incidence in Turkish pregnant women. Gynecol Endocrinol. 2009;25:387-91.

269. Pratt DE, Kaberlein G, Dudkiewicz A, Karande V, Gleicher N. The association of antithyroid antibodies in euthyroid nonpregnant women with recurrent first trimester abortions in the next pregnancy. Fertil Steril. 1993;60:1001-5.

270. Kim CH, Chae HD, Kang BM, Chang YS. Influence of antithyroid antibodies in euthyroid women on in vitro fertilization-embryo transfer outcome. Am J Reprod Immunol. 1998;40:2-8.

271. Glinoer D, Soto MF, Bourdoux P, Lejeune B, Delange F, Lemone $M$, et al. Pregnancy in patients with mild thyroid abnormalities: maternal and neonatal repercussions. J Clin Endocrinol Metab. 1991;73:421-7.

272. Mecacci F, Parretti E, Cioni R, Lucchetti R, Magrini A, La Torre P, et al. Thyroid autoimmunity and its association with non-organspecific antibodies and subclinical alterations of thyroid function in women with a history of pregnancy loss or preeclampsia. $\mathrm{J}$ Reprod Immunol. 2000;46:39-50.

273. Bussen SS, Steck T. Thyroid antibodies and their relation to antithrombin antibodies, anticardiolipin antibodies and lupus anticoagulant in women with recurrent spontaneous abortions (antithyroid, anticardiolipin and antithrombin autoantibodies and lupus anticoagulant in habitual aborters). Eur J Obstet Gynecol Reprod Biol. 1997;74:139-43.

274. Dendrinos S, Papasteriades C, Tarassi K, Christodoulakos G, Prasinos $G$, Creatsas $G$. Thyroid autoimmunity in patients with recurrent spontaneous miscarriages. Gynecol Endocrinol. 2000;14:270-4.

275. Esplin MS, Branch DW, Silver R, Stagnaro-Green A. Thyroid autoantibodies are not associated with recurrent pregnancy loss. Am J Obstet Gynecol. 1998;179:1583-6.

276. De Groot L, Abalovich M, Alexander EK, Amino N, Barbour L, Cobin $\mathrm{RH}$, et al. Management of thyroid dysfunction during pregnancy and postpartum: an Endocrine Society clinical practice guideline. J Clin Endocrinol Metab. 2012;97:2543-65.

277. Reid SM, Middleton P, Cossich MC, Crowther CA. Interventions for clinical and subclinical hypothyroidism in pregnancy. Cochrane Database Syst Rev. 2010:CD007752.

278. Alexander EK, Marqusee E, Lawrence J, Jarolim P, Fischer GA, Larsen PR. Timing and magnitude of increases in levothyroxine requirements during pregnancy in women with hypothyroidism. N Engl J Med. 2004;351:241-9.

279. Abalovich M, Alcaraz G, Kleiman-Rubinsztein J, Pavlove MM, Cornelio $C$, Levalle $O$, et al. The relationship of preconception thyrotropin levels to requirements for increasing the levothyroxine dose during pregnancy in women with primary hypothyroidism. Thyroid. 2010;20:1175-8. 